\title{
Conceptualizing career insecurity: Toward a better understanding and measurement of a multidimensional construct
}

\section{Daniel Spurk $^{1} \quad$ Annabelle Hofer ${ }^{1}$ [ Cuyper $^{2}$ (1) | Hans De Witte ${ }^{2,3}$ (1)}

\footnotetext{
${ }^{1}$ Department of Work and Organizational Psychology, University of Bern, Bern, Switzerland

${ }^{2}$ Research Group Work, Organizational and Personnel Psychology, KU Leuven, Leuven, Belgium

${ }^{3}$ Optentia Research Focus Area, North-West University, Vanderbijlpark, South Africa

\section{Correspondence}

Daniel Spurk, University of Bern, Institute of Psychology, Fabrikstrasse 8, 3012 Bern, Switzerland.

Email:daniel.spurk@unibe.ch
}

Daniel Spurk and Annabelle Hofer shared first authorship.

The copyright line for this article was changed on 31 January 2022 after original online publication.

\section{Funding information}

Schweizerischer Nationalfonds zur Förderung der Wissenschaftlichen Forschung,

Grant/Award Number: 100019_162680

\begin{abstract}
Applying qualitative and quantitative analyses across four studies and seven samples, we clarified the meaning and developed a new measure of career insecurity. Career insecurity is defined as "an individual's thoughts and worries that central content aspects of one's future career might possibly develop in an undesired manner." The new Multidimensional Career Insecurity Scale (MU-Cl-S) measures eight career insecurity $(\mathrm{Cl})$ dimensions: (1) $\mathrm{Cl}$-Career opportunities; (2) $\mathrm{Cl}$-Decreased prestige and qualification requirements of the employment; (3) $\mathrm{Cl}$-Contractual employment conditions; (4) $\mathrm{Cl}$-Unemployment; (5) $\mathrm{Cl}$-Change of workplace; (6) Cl-Retirement; (7) Cl-Work-nonwork interactions; and (8) $\mathrm{Cl}$-Discrepancy between individual resources and work demands. Across all studies, the $\mathrm{MU}-\mathrm{Cl}-\mathrm{S}$ showed excellent psychometric properties (e.g., factor loadings of all items and internal consistencies of all dimensions) and high levels of construct validity (e.g., theoretically assumed factorial structure and discriminant and convergent validity). The analyses showed concurrent, predictive, and incremental validity beyond neuroticism and other job and career insecurity measures for predicting health and well-being,
\end{abstract}


job performance, career success, and career attitudes. The results provide a comprehensive assessment and investigation of career-related insecurity perceptions in the current labor market. Moreover, the results offer theoretical and practical implications for individual career planning, career counseling, and organizational career management.

\section{KEYWORDS}

career insecurity, career management, scale development

\section{1 | INTRODUCTION}

Today's careers are inherently insecure (e.g., Colakoglu, 2011; Hall et al., 2018; Spurk et al., 2016; Sullivan \& Baruch, 2009). This is related to ongoing changes in, for example, organizational restructuring, global business competition, and technological advancements (e.g., digitization). Moreover, specific events, for example, economic crises or the COVID-19 pandemic, can raise perceptions of career insecurity (Spurk \& Straub, 2020). Accordingly, career insecurity is attracting increased scholarly attention (Colakoglu, 2011; Ortlieb \& Weiss, 2018; Spurk et al., 2016; Trevor-Roberts, 2006).

Career development can be defined as the sequence of different jobs and related occupational experiences spanning a person's life (Arthur et al., 1989; Greenhaus \& Kossek, 2014). From a conceptual/theoretical perspective, career theories describe career development as a multidimensional endeavor: Individuals need to consider and integrate different content domains (e.g., developmental tasks and life roles) during their career (Greenhaus \& Kossek, 2014; Hall et al., 2018; Sullivan \& Baruch, 2009; Super, 1953). Likewise, career insecurity is presumably multidimensional: Individuals might experience insecurity when considering different content domains of their future career. Yet, existing conceptualizations of career insecurity do not specify content domains of insecurity. They are one dimensional (e.g., Colakoglu, 2011; Höge et al., 2012; Ortlieb \& Weiss, 2018; Spurk et al., 2016) and may not cover the full breadth and dimensionality of the underlying career construct (Hinkin, 1995; Trevor-Roberts, 2006). This is problematic because the understanding of an individual's experience of career insecurity and its idiosyncratic aspects is important for career management (Trevor-Roberts, 2006).

From a psychometrical perspective, by relying primarily on ad hoc measures, the construction and validation process of past career insecurity scales remains relatively unclear (Colakoglu, 2011; Höge et al., 2012). This situation is particularly problematic because, in our view, past measures of career insecurity are confounded by aspects of perceived low employability (e.g., Colakoglu, 2011) or lack of confidence in career goal attainment and career planning (e.g., Höge et al., 2012). In sum, although career insecurity represents an important career construct, these shortcomings hamper a clear interpretation of career insecurity research because (a) it remains unclear how employees experience and understand multidimensional career insecurity; (b) past conceptualizations might be confounded by similar other constructs; and (c) existing measurements focus on narrow or unspecified overall aspects of career insecurity.

Against this background, this article has three major aims. Our first aim is to contribute to the conceptual clarification of multidimensional career insecurity. This will contribute to past insecurity and career research in the workplace by providing a detailed clarification of a construct with increasing importance in the world of work. Moreover, it will provide a solid, rich, and detailed conceptual basis for future research.

Our second aim is to develop and validate a psychometrically sound, multidimensional measure of career insecurity, accounting for best-practice recommendations in scale development (e.g., Hinkin, 1995; Wright et al., 2017). Specifically, we aim to focus on aspects of content and construct validity (convergent and discriminant validity) by empirically comparing multidimensional career insecurity with one-dimensional career insecurity, job insecurity, perceived 
low employability, and perceived career barriers. This second aim will expand on previous research on career insecurity that primarily applied ad hoc measures. Such a validated multidimensional measure can not only be applied in future research but also serves as an important evaluation measure within applied settings like personnel development, career management, and career counseling. For example, the new scale can be used as an overall screening instrument to evaluate the degree to which career insecurity is a topic for an individual career actor or within a specific organization (e.g., as part of an employee survey). Additionally, by measuring the expression of specific career insecurity content dimensions, the new scale can also be applied to derive customized solutions in career counseling or personnel and organizational management.

Our third aim is to establish the criterion validity of the scale by showing a differentiated empirical picture of (incremental) relationships with career insecurity outcomes relevant for organizations and individual career development (e.g., health/well-being, job performance, career success, and career attitudes). By applying theories from stress and career research, this will contribute to the theoretical and empirical understanding of career insecurity and directly inform occupational health and career research. Moreover, it will also be informative for applied settings, such as employee retention or performance management. In sum, the developed and validated Multidimensional Career Insecurity Scale (MU-Cl-S) will enable comprehensive overall measurement of the higher-order construct of career insecurity and a facet-rich investigation of the separate career insecurity dimensions in future research.

To reach these aims, we conducted four studies comprising seven independent samples (an overview of all studies, study aims, assigned samples, and sample characteristics can be seen in the Online Supplements: Tables S1 and S2). Study 1 is related to conceptual advancement: We clarify the nature of multidimensional career insecurity based on the literature, conducting qualitative interviews with employees and a workshop with career counselors (Sample \#1, overall $N=30$ ) and surveying scholars with expertise in applied psychology and careers research (Sample \#2, $N=10$ ). Study 2 is related to scale development: We generate items, apply an item-sorting task (Sample \#3, $N=16$ ) to ensure content adequacy, present results on psychometric properties and factorial structure (Sample \#4, $N=404$; Sample \#5, $N=1091$; Sample \#6, $N=182$; Sample \#7, N = 1443), and test for construct validity (i.e., discriminant and convergent validity; Sample \#4 and \#5). Studies 3 and 4 are related to criterion validity. In Study 3, we investigate concurrent validity, predictive validity, and the incremental validity of the overall scale when predicting diverse outcomes (e.g., physical symptoms, in-role behavior, career satisfaction, career commitment) within one cross-sectional (Sample \#5) and one time-lagged (Sample \#6) dataset. In Study 4, we examine aspects of the differential predictive nature of the eight identified career insecurity dimensions by conducting relative weights analyses with several outcomes (Sample \#7).

\section{2 | STUDY 1: CONCEPTUALIZING AND UNDERSTANDING CAREER INSECURITY}

\section{1 | Part 1: Conceptual clarification and similar constructs}

\subsection{1 | Past definitions and measures of career insecurity}

While career insecurity is seen as a fundamental experience within an individual's career, past research has not explicitly defined the construct (e.g., Trevor-Roberts, 2006) or clearly differentiated it from related constructs. For example, Tien et al. (2005) defined career insecurity as "any factors that make individuals feel uncertain of their career future" (p. 154). This definition seems to confound predictors (i.e., factors that make individuals feel) of career insecurity with the construct itself. Moreover, the study focused on career insecurity among college students and hence did not account for relevant issues in the labor market.

As another example, Colakoglu (2011) stated that individuals experience career insecurity "when they feel powerless to maintain continuous employment (i.e., employability) in their careers" (p. 50). Following this definition (sample item: "I am worried that I will have times during which I don't have any paid employment"), career insecurity is narrowed down to aspects of continuous employment (vs. unemployment), which conceptually is very close to perceived (low) employability and job insecurity (De Cuyper et al., 2012; Shoss, 2017). 
A third example comes from Höge et al. (2012), who defined career insecurity as an individual's insecurity about the attainment of mid- to long-term career goals (see also Spurk et al., 2016). Career insecurity is conceptualized as a one-dimensional construct related to individual goals, but without more detail. Moreover, the four-item scale of Höge et al. (2012) includes items that do not cover career insecurity directly but are conceptually similar to other constructs. For example, the item "I am not sure whether I shall achieve my career aims" taps into self-efficacy (Chen et al., 2001), while "It is difficult for me to plan my professional future" taps into career planning (Gould, 1979).

\subsection{2 | Core characteristics of career insecurity}

Although divergent, existing definitions share some common features that, together with insights from research on related insecurity constructs (e.g., job insecurity) and career development, help to identity four core characteristics of career insecurity.

\section{Insecurity component}

Career insecurity exists between complete predictability and considerable unsureness about how one's future career might look (Trevor-Roberts, 2006). Hence, similar to research on other work-related insecurity perceptions, such as job insecurity (Cheng \& Chan, 2008; De Witte, 2005; Shoss, 2017), not knowing exactly what the future will bring and associated thoughts and worries are at the core of career insecurity. In that sense, career insecurity has a negative connotation, as it involves having thoughts and/or worries that something undesired might occur in the future. In other words, when feeling insecure about their career, (a) individuals are not sure (i.e., it might happen or not) (b) whether career-related aspects will change in an undesired way ${ }^{1}$. This is associated with thoughts and worries. Indeed, past insecurity research sometimes distinguished between cognitive (i.e., "thinking about") and affective (i.e., "feelings about") insecurity components (Jiang \& Lavaysse, 2018; Pienaar et al., 2013). Both components of insecurity are meaningful and should be included in the career insecurity construct.

\section{Future time perspective}

Career insecurity includes short-term and mid- to long-term insecurities (Höge et al., 2012; Spurk et al., 2016; TrevorRoberts, 2006). In other words, people might be thinking and worrying about career contents that are relatively close (e.g., potentially missed next career developmental opportunities) and/or relatively far in the future (e.g., potential loss of career developmental opportunities in the late career). For example, it has been shown that contractors may feel secure about their opportunities in the short term (because they might easily find other options) but insecure about their long-term career development (Bambacas \& Kulik, 2013). This aligns with career developmental theories that assume that careers and related experiences continuously evolve over time (Greenhaus \& Kossek, 2014; Hall et al., 2018; Sullivan \& Baruch, 2009; Super, 1953).

\section{Multidimensionality}

Career development is a multifaceted, individualized process that taps into different content domains (e.g., Greenhaus \& Kossek, 2014; C. I. S. G. Lee et al., 2014; Shockley et al., 2016; Sullivan \& Baruch, 2009). Individuals may not only worry about their overall career but also develop specific thoughts and worries that relate to different content domains (e.g., the employer or retirement regulations). These specific content-related thoughts and worries are based to some extent on the more general perception that the career might be insecure: Individuals may cognitively and affectively process this general feeling into a more aspectual evaluation. Examples are thoughts and worries about different career developmental tasks, such as potentially not establishing one's position, not developing enough expertise, not holding up the standards and status of the current employment and related aspects, problems with integrating work and non-work life, or unsureness about retirement issues (Akkermans \& Kubasch, 2017; Greenhaus \& Kossek, 2014; Lent \& Brown, 2013; Wang \& Wanberg, 2017). In other words, we approach career insecurity as a 
multidimensional construct, consisting of distinct dimensions that capture employees' thoughts and worries regarding central aspects of their future career development. Hence, the central career aspects should reflect some of the most relevant and frequently considered aspects of insecurity of the majority of a population (e.g., employees). Because these dimensions share a common core insecurity, they should be moderately related but nonetheless distinct from each other.

\section{Context: Intra- and extra-organizational development}

Because career development involves a sequence of different jobs and related occupational experiences spanning a person's life (Arthur et al., 1989; Greenhaus \& Kossek, 2014), careers can cross organizational boundaries (Hall et al., 2018). Hence, the content domain of career insecurity includes aspects of both intra- and extra-organizational development. In other words, individuals might think and worry about missing career opportunities within or outside the current employer or about potential undesired employment changes with the current or with another employer (e.g., potential undesired changes in the occupation or a potentially involuntary move to a totally different field of expertise or employer). Integrating these four aspects, we offer the following definition:

"Career insecurity is an individual's thoughts and worries that central content aspects of one's future career might possibly develop in an undesired manner."

\subsubsection{Commonalities and differences with similar constructs}

Career insecurity is similar yet distinct from constructs that focus either on insecurity in the work domain or on perceptions related to detrimental career development. To clarify the theoretical nature of career insecurity vis-à-vis related constructs, we will compare career insecurity with (a) job insecurity, which is the most frequently studied insecurity variable in the work domain (Cheng \& Chan, 2008; Shoss, 2017); (b) perceived low employability as a maladaptive self-evaluation regarding future employment prospects (Akkermans \& Kubasch, 2017); and (c) perceived career barriers, which are central career stressors associated with undesired career outcomes (Hirschi \& Freund, 2014; Ng \& Feldman, 2014b).

\section{Job insecurity}

Job insecurity refers to the perceived threat and worry of losing one's current job (i.e., quantitative job insecurity) or aspects of one's job (e.g., stimulating job content; Greenhalgh \& Rosenblatt, 1984) in the near future (Ellonen \& Nätti, 2015; Vander Elst et al., 2016). Like job insecurity, career insecurity is future-directed and includes thoughts and worries about the possibility that something undesired might happen-not that something negatively will occur for sure. Hence, both job and career insecurity have an insecurity component at their core, and both represent a perceived threat for the individual.

However, there also are differences between job insecurity and career insecurity. First, they differ regarding their future time perspective. Job insecurity focuses predominantly on short-term insecurities (e.g., Ellonen \& Nätti, 2015; Vander Elst et al., 2016). An illustration is the sample item from De Witte (2000): "I think I might lose my job in the near future." In contrast, career insecurity spans the entire career and thus focuses on short-term, mid-term, and longterm thoughts and worries. Second, job insecurity refers to the current job in the current organization (Shoss, 2017). Conversely, although career insecurity perceptions might be related to the current organizational career path, career insecurity is not restricted to the current organization. Third, job insecurity concerns not only the job as such but also valuable characteristics of the current job (e.g., stimulating job content or autonomy of a given task or overcrowded offices leading to daily work interruptions; Hellgren et al., 1999; Shoss, 2017). Meanwhile, career insecurity concerns broader career developmental aspects (e.g., unemployment, overall career goals, unemployment, career opportunities, or retirement) and therefore does not focus on job characteristics per se. 
Moreover, job insecurity does not automatically imply career insecurity and vice versa. Employees may feel insecure about their job yet not about their career. Consider the example of an early career academic scientist, who may feel insecure about the current job because financing is not stable but still quite sure about how the career will develop. Similarly, imagine a talent working in a startup that might possibly not survive (high job insecurity) who nevertheless has low career insecurity because the talent might easily find other opportunities in the world of work. Conversely, employees may feel insecure about their career but not about their job. For example, a manufacturer or deliverer might have a secure job but still face severe career insecurity due to digitization or automation in the mid- to long term.

\section{Perceived low employability}

Perceived employability can be conceptualized as an individual's appraisal of available job opportunities in the internal and/or external labor market (De Cuyper et al., 2011; Rothwell \& Arnold, 2007). Perceived low employability describes a situation in which individuals do not see many alternative jobs, and this has some resemblance to the notion of career insecurity. Both constructs refer to negative career-related experiences, and they both include perceptions of the internal and external organizational labor market. However, there are differences in terms of experiencing insecurity and multidimensionality. First, perceived low employability consists of the perception that alternative job opportunities are (not possibly) few or unavailable. Second, the target of low perceived employability refers only to other potential employment (e.g., other jobs within the current organization or another organization), whereas career insecurity includes content aspects of career development that presumably go beyond such employment issues (e.g., work non-work issues, developmental opportunities, retirement issues).

\section{Perceived career barriers}

Perceived career barriers are perceived external obstacles to occupational goals (Holland et al., 1980; Lent \& Brown, 2013). Like career insecurity, they represent an unpleasant evaluation related to hurdles inside and/or outside the organization, including non-work barriers, which are detrimental to career development (Ng \& Feldman, 2014b). Yet, there are differences in terms of the time perspective and insecurity. First, perceived career barriers involve appraisals about present (not future-oriented) hurdles (e.g., labor market, family, or organization) for an individual's career development, whereas career insecurity represent appraisals of the future. Second, perceived career barriers do not have an insecurity component at their core.

\subsection{Part 2: Identification of career insecurity dimensions}

Next, we sought to identify the different content aspects, seen as separate dimensions within a multidimensional conceptualization of career insecurity. In a first step, we conducted a literature search to identify different content domains of career insecurity. Based on this, we named and described potential career insecurity dimensions. In a second step, we conducted semi-structured qualitative interviews and a workshop with career counselors to integrate the idiosyncratic understanding of employees about career insecurity within the initially described career insecurity dimensions. In addition, we extended the initial dimensions by identifying two dimensions that were not identified in the literature review yet advanced in the interviews and workshops. We relied on thematic analysis to derive and describe the emerging career insecurity dimensions (Braun \& Clarke, 2006). In a third step, we conducted a survey with applied psychology and careers researchers to refine the career insecurity dimensions.

\subsection{1 | Step 1: Past literature}

We searched comprehensive scientific databases (e.g., SCOPUS and Google Scholar) for literature related to career insecurities. We searched the fields of social sciences and economics/management to identify studies relevant to the 
field of applied psychology. ${ }^{2}$ We excluded articles that mentioned insecurity as a side theme (e.g., the study was conducted in times of economic crisis, but insecurity was not a central study variable) or did not provide a clear description or definition of the content of the construct (e.g., the study referred to insecurity or a similar construct, but it was unclear whether it was about careers or jobs or other targets). This procedure resulted in 15 articles.

Based on these articles, a systematic categorization of relevant content aspects was performed by the first three authors. On the lowest level, a single individual content aspect was included in the categorization process when the target of the insecurity was clear and linked to the career. Regarding the validity of codes, a content aspect that referred to "exit out of employment" was included because it represents a career developmental task, whereas "work task uncertainty" was not included because it represents a content aspect of the current job (i.e., job characteristic) but not the career. Altogether, 17 individual content aspects were identified (e.g., potential lack of upward mobility, undesired developmental opportunities, maybe not enough pension coverage, or presumably problematic exit out of working life). Subsequently, the 17 individual content aspects were sorted into potential themes based on the lowest common denominator (i.e., thematic analysis; Braun \& Clarke, 2006). Subsequently, themes were categorized into overarching dimensions (i.e., the career insecurity dimensions). The dimensions were labeled and initially described based on the "essence" of what each dimension is about (Braun \& Clarke, 2006). In cases of non-agreement between the coders about the categorization of individual content aspects or about describing a dimension, the authors reached consensus through discussion. The resulting descriptions of the dimensions were used as a basis for further coding within the qualitative interviews in the next step.

Van Eetveldt et al. (2013) used career insecurity as a term and defined it as "the perception of a potential threat to career mobility and career progress." The described items for measuring career insecurity in this quantitative study also tapped into aspects like "opportunities for personal development" or "career opportunities." Hence, their study provided information about content aspects that were later coded under the career insecurity dimension of career opportunities. Colakoglu (2011) defined career insecurity as "the sense of powerlessness to maintain desired employability in one's career" (p. 48). The items were close to this definition. Hence, the study provided information about content aspects that were categorized under the career insecurity dimension of unemployment. Scott-Marshall (2010) referred to work-related insecurities and conceptualized several content areas (dimensions) that are relevant for career insecurity: earnings insecurity was categorized under the career insecurity dimension of contractual employment conditions, pension coverage insecurity was categorized under the dimension of retirement issues, and work-life balance insecurity was categorized under the dimension of work-nonwork interactions.

In sum, we identified six potential career insecurity dimensions about which individuals might be thinking or worrying. These are thoughts and worries related to (a) career opportunities (e.g., lack of upward mobility or developmental opportunities in the future; Körner et al., 2015; Van Eetveldt et al., 2013); (b) prestige \& qualification requirements of employment (e.g., getting jobs with low status or low qualification requirements; Colakoglu, 2011; Scott-Marshall, 2010); (c) contractual employment conditions (e.g., temporary employment or part-time work; Schmitt, 2012; ScottMarshall, 2010); (d) unemployment (e.g., job loss and longer periods of unemployment; Colakoglu, 2011; Pavlova \& Silbereisen, 2014); (e) retirement issues (e.g., not enough pension coverage or problematic exit out of working life; Gesthuizen \& Wolbers, 2011; Scott-Marshall, 2010); and (f) work-nonwork interactions (e.g., work-life balance insecurity; Scott-Marshall, 2010; Van Eetveldt et al., 2013).

\subsection{2 | Step 2: Qualitative interviews and career counselor workshop (Sample \#1)}

In 2016, we conducted qualitative in-depth interviews with employees and a workshop (comparable to a focus group) with career counselors to (a) verify the initially identified six dimensions (deductive approach); (b) identify potential dimensions that were not found in past research (inductive approach); and (c) better understand the meaning and content of the initially identified and new dimensions (inductive approach). Qualitative interviews and workshops are 
frequently utilized to identify understandings/dimensions of underlying constructs, for example, when identifying dimensions of career success (Shockley et al., 2016) or insecurity perceptions (Tien et al., 2005).

The interview participants were recruited through social media and the research teams' networks. The participants included 17 employees (eight women, nine men) from Germany ( $N=10,58.8 \%)$ or German-speaking Switzerland $(N=7,41.2 \%)$. The interview participants were between 20 and 55 years old (category 1: $20-30$ years $=41.2 \%$; category 2: $31-40$ years $=29.4 \%$; category $3: 41-55=29.4 \%$; modus $=1$; median $=2$ ). They were paid 15 Euros (approx. 17.6 U.S. dollars) in Germany and 20 Swiss francs (approx. 21.3 U.S. dollars) in Switzerland per interview. We interviewed persons who worked at least within $50 \%$ of a full-time-equivalent position, indicating a steady work status (Kukla et al., 2019). For these employees, the work domain and related experiences should be relevant to the participants' life. Furthermore, the participants were selected to represent a diverse group in terms of educational level (e.g., academics and non-academics) and occupied jobs (e.g., druggist, actor, physician, and psychologist) to get a broader overview of relevant career insecurity aspects (Creswell, 2009; Shockley et al., 2016). Generally, the interview followed a predefined semi-structured interview guideline. After an initial discussion about the past career of the participants, we asked questions about the meaning of career insecurity (e.g., "Which aspects of your future career do you perceive as insecure?" or "What thoughts and worries do you have when thinking about your future career?"). All interviews were audio recorded and transcribed for further analyses. The interviews lasted $30.12 \mathrm{~min}$ on average $(S D=11.03)$.

Besides interviewing employees, we conducted a workshop with career counselors from Switzerland ( $N=13$; eight women, five men). The career counselors were not incentivized, but they were told that their participation would be helpful for improving the understanding of career insecurity. These career counselors discussed aspects of career insecurity they experienced in their work with career counseling clients (e.g., "Regarding the work with your clients, which thoughts and worries do they report when they think about their future career?"). Written notes and flipcharts made by the workshop moderators and written notes made by the career counselor group were used as material for further analysis.

The total number $(N=30)$ of participants was determined based on the saturation method (Saumure \& Given, 2008), whereby data are collected to the point at which subsequent participants fail to provide unique information on the topic under investigation. Evidence of saturation was based on coding subsets of the data. The first subset consisted of six interviewees, the next subset consisted of the workshop members, the third subset included the next six interviewees, and finally the last coding round, where saturation was achieved based on a lack of new information, included five interviewees. A sample size of 30 participants meets the recommendation of at least 25 participants for qualitative research aimed at item development (Sandelowski, 1995) and of 20-30 for non-ethnographic qualitative interviewing (Warren, 2001). The whole project and data collection were approved by the ethical standards board of the Institute of Psychology of the University of Bern, Switzerland.

Both the transcripts from the interviews and the materials from the workshop were combined to verify the initially identified career insecurity dimensions and to potentially identify new career insecurity dimensions. This should ensure that the multidimensional conceptualization of career insecurity developed here is fine-graded in terms of insecurity content and covers the full breadth and dimensionality of the underlying construct. Based on thematic analysis (Braun \& Clarke, 2006), single individual aspects of career insecurity were identified. One individual aspect always represented one single content unit reflecting a thought or worry about the future career. Individual career insecurity aspects were (a) added by the raters to either one of the initially identified six dimensions or (b) added to a new dimension together with other aspects of similar meaning. This categorization process was performed by one of the authors that share the first authorship and two assistants not previously involved in the research project. The interrater reliability was $\mathrm{K}=.93$.

After the individual career insecurity aspects were categorized into new career insecurity dimensions, the total number of new dimensions was reduced by collapsing them with common underlying themes. For instance, different types of mobility-related insecurities were included into one new dimension (cf. below "Career Insecurity-Change of 
workplace"), instead of treating them as different dimensions (e.g., within versus outside the current organization). Finally, the labels and content descriptions of the initially derived career insecurity dimensions from step 1 were adapted based on the new content of the qualitatively generated career insecurity aspects, and labels and descriptions were assigned to the newly added career insecurity dimensions. For example, qualitative analyses showed that the dimension prestige \& qualification requirements of employment seems predominantly and genuinely about a decrease and not an increase in both prestige and qualification. Therefore, we added a "decrease" to the labeling of that dimension (i.e., $\mathrm{Cl}$-Decreased prestige \& qualification requirements of future employment). This process was performed by the first three authors. In cases of non-agreement on the categorized career insecurity aspects or the career insecurity dimension labels and descriptions, discrepancies were resolved via discussion. The labels and descriptions of the career insecurity dimensions were refined based on the essence of what each dimension is about (Braun \& Clarke, 2006). Finally, this procedure resulted in adding two more career insecurity dimensions to the six that were initially identified: Career Insecurity (Cl)-Change of workplace, and Cl-Discrepancy between individual resources/work demands (see Table 1 for an overview of all dimensions).

\subsubsection{Step 3: Refinement based on a scholarly expert survey (Sample \#2)}

In a final step in September 2016, we invited ten international scholars (Belgium, Germany, Switzerland, the Netherlands, the United States) from the fields of applied psychology and career research to participate in an online survey and presented them with our definition of career insecurity as well as the eight career insecurity dimensions and their descriptions. The international scholars were not incentivized but were told that their expertise would be helpful for developing the conceptualization of multidimensional career insecurity. The goals of this scholar survey were to evaluate (a) if the identified career insecurity dimensions are exhaustive and (b) if the eight career insecurity dimensions and their descriptions are clearly understandable and possess content validity. Regarding exhaustiveness, $90.0 \%$ of the scholars agreed that the dimensions represent the definition and the construct of career insecurity entirely. Two scholars proposed each one additional dimension (i.e., "external macro conditions" and "social sphere at work"). We decided not to include these dimensions because external macro conditions are better seen as contextual predictors of career insecurity and not as a direct feature of one's own career, and social sphere at work is strongly related to current job characteristics and is thus better seen as one aspect of job insecurity (see above). Regarding the dimensional descriptions, if the scholars indicated a meaningful mismatch between the dimension description and its label (this was the case for $\mathrm{Cl}$-Decreased prestige \& qualification requirements of future employment), we refined the dimension description slightly to enhance the fit to its label.

\section{3 | Discussion study 1}

Based on past research, qualitative interviews, a workshop, and the expertise of international scholars, we provided a conceptual clarification and better understanding of the meaning of career insecurity and its multidimensional nature. Considering that career development per se is a multifaceted, individualized process (C. I. S. G. Lee et al., 2014; Lent \& Brown, 2013; Shockley et al., 2016; Sullivan \& Baruch, 2009), we identified eight different career insecurity dimensions that tap into diverse content domains and therefore provide concrete insights about the nature and content of the construct. Hence, compared to one-dimensional career insecurity conceptualizations, our conceptualization provides a more comprehensive basis for the study of career insecurity. Moreover, we clarified that career insecurity is a unique construct that should be discriminated from (a) job insecurity; (b) perceived low employability; and (c) perceived career barriers. 


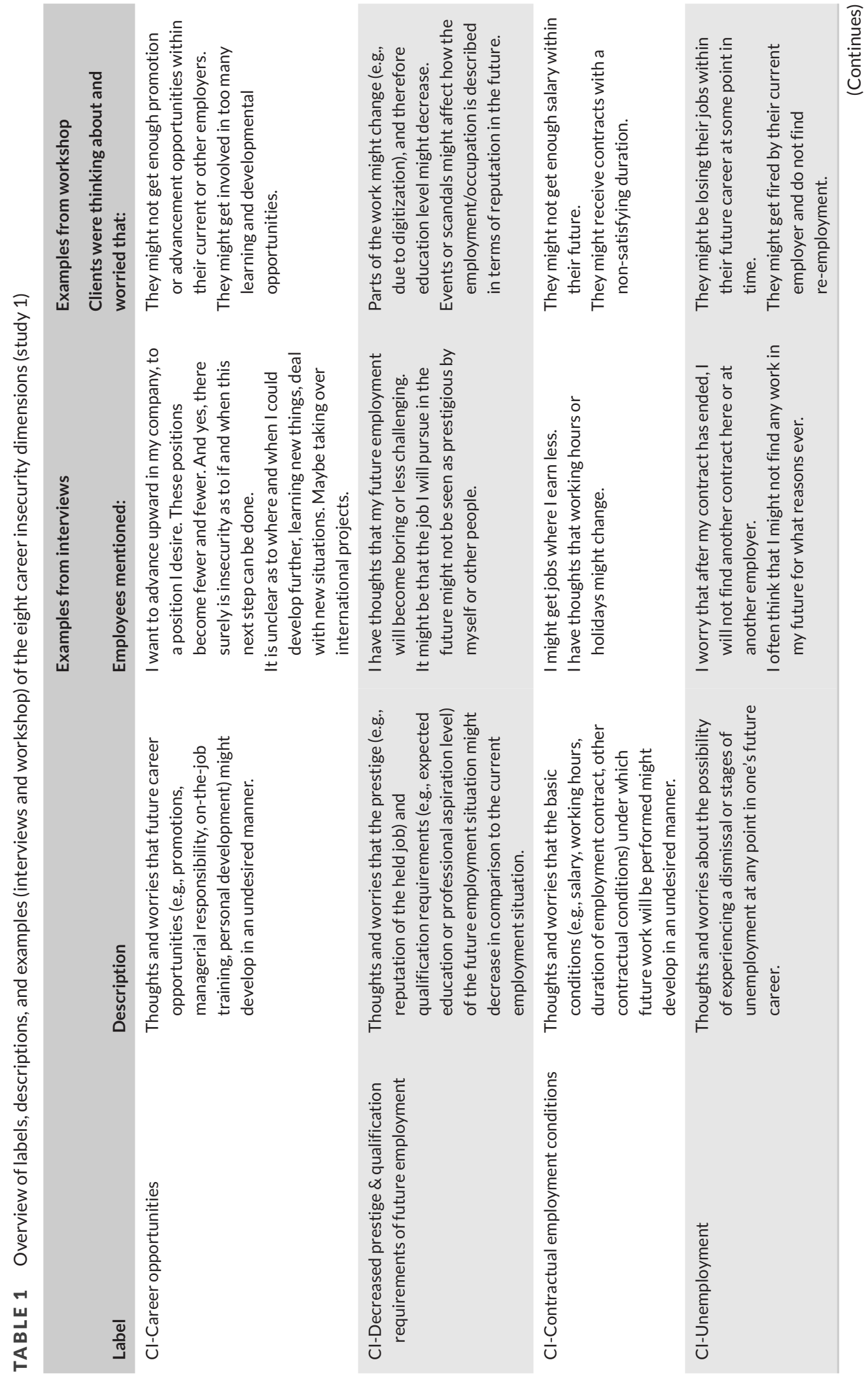



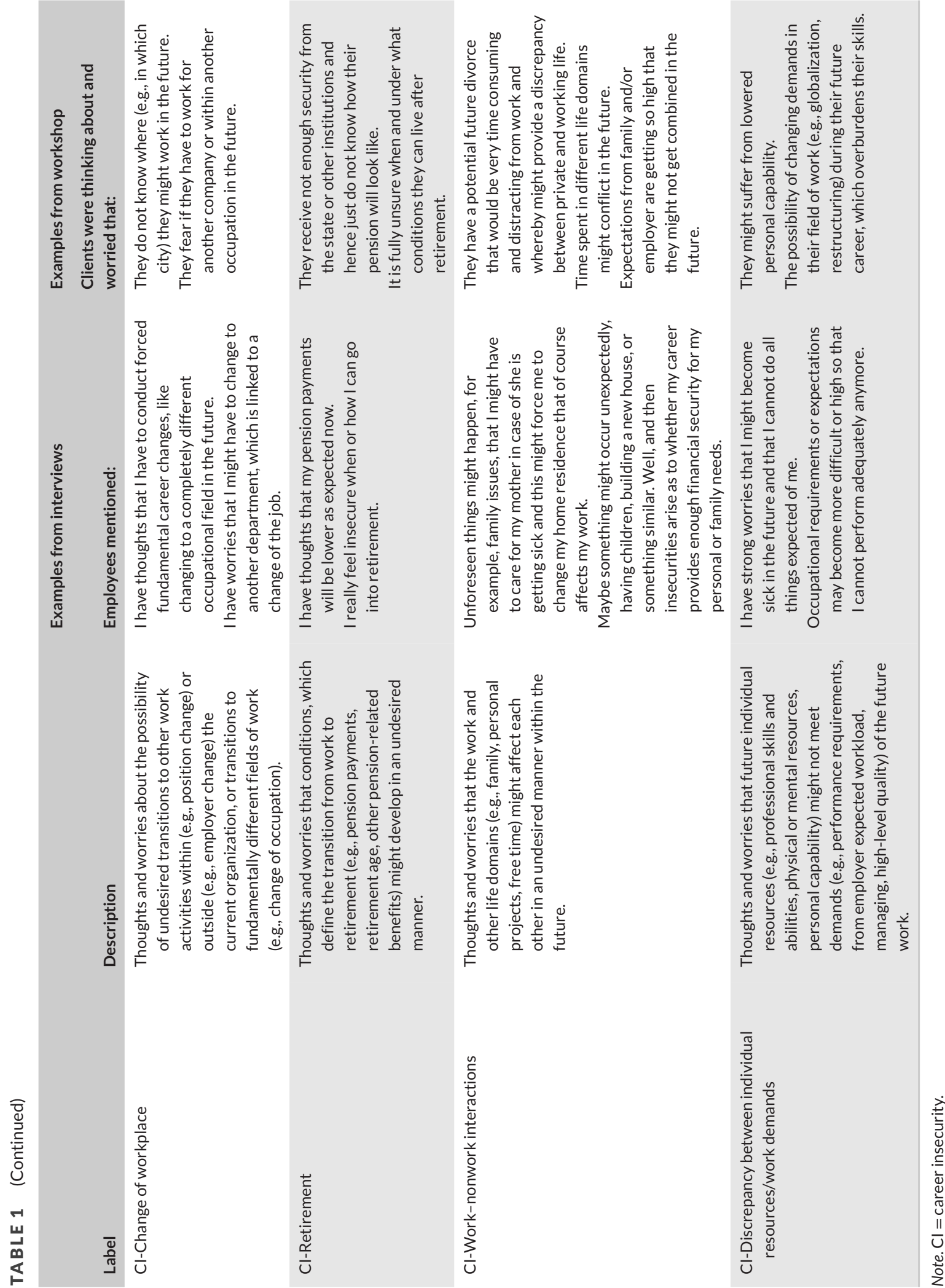


\section{I STUDY 2: THE MEASUREMENT OF CAREER INSECURITY-DEVELOPMENT AND INITIAL VALIDATION OF A MULTIDIMENSIONAL CAREER INSECURITY SCALE}

The aim of the second study was-based on Study 1's conceptualization-the development of the MU-Cl-S, following state-of-the-art scale construction methods (Hinkin, 1995; Wright et al., 2017).

\section{1 | Part 1: Item development and selection}

Based on the descriptions of the eight career insecurity dimensions from Table 1, the first three authors independently developed a minimum of five items per dimension. The items were formulated to capture both cognitive (e.g., "Chance are..." or "I wonder...") and affective (e.g., "I fear..." or "I worry...") career insecurity components. To align our new measure with research on the insecurity domain in the workplace, we inspected job and other career insecurity measures for suitable expressions, tapping varying degrees of insecurity (e.g., Colakoglu, 2011; Hellgren et al., 1999; Vander Elst et al., 2014). Following Hinkin's (1998) recommendation, we created items that were easy to understand, not double-barreled, and consistent in terms of perspective. This procedure resulted in a pool of 120 items.

\subsubsection{Content validity of the scale (Sample \#3)}

To establish the content validity of the scale, we conducted an item-sort task (e.g., Anderson \& Gerbing, 1991), where items that could not clearly be assigned to their corresponding career insecurity dimension were identified and excluded. In October 2016, we sampled psychologists $(N=16)$ studying or working at universities for this item-sort task because they possess the necessary conceptual ability (Brady et al., 2017; Hinkin, 1998) and are experts in matching item content to respective factor descriptions. The characteristics of the respondents were as follows: $75 \%$ female, $25 \%$ male; age: $M=27.00, S D=2.13$; and $56.3 \%$ had a bachelor's degree (43.7\% a master's or equal degree). The psychologists were not incentivized, but they were told that their participation would be helpful for the scale validation process. The participants had to assign every item to the most appropriate career insecurity dimension (for similar approaches, see Brady et al., 2017; Hirschi et al., 2018). Ten items that were not correctly assigned to the corresponding career insecurity dimension by more than $25 \%$ of the participants were excluded (cf. Hirschi et al., 2018).

Based on the remaining items $(N=110)$, the first three authors discussed and chose items for further use, which tapped into different aspects of each career insecurity dimension content-wise and were easiest to understand. For example, we chose items about retirement age and pension payment instead of retirement age and retirement timing to achieve a relatively heterogeneous measurement of the dimension $\mathrm{Cl}$-Retirement. Furthermore, we targeted four items per dimension to ensure an optimum mix of economical and reliable measurement (Brady et al., 2017; Hinkin, 1995, 1998). Therefore, about eight items per dimension were selected to have the possibility to choose among a sufficient number of items via exploratory factor analysis (EFA) in a further survey (see below). Based on these discussions, an item pool of 63 items was retained.

\subsection{2 | Exploratory factor analysis and final item selection ${ }^{3}$}

\section{Sample and procedure (Sample \#4)}

In 2016, participants were recruited through a German online-access research panel company. The panel provider paid 3.35 Euros (approx. 4 U.S. dollars) to each participant. None of the participants earned money with online surveys professionally, and all held a regularly paid job (at least $50 \%$ of a full-time position). Based on data quality checks related to 
carelessness and speeding (DeSimone et al., 2015), 8.18\% of the participants were excluded, resulting in a final sample size of 404 (49.3\% men). The respondents were $M=38.21(S D=9.23$ ) years old, came from a large variety of industry sectors, and worked on average $37.18(S D=5.44) \mathrm{h}$ per week, and about half of them held a university degree $(50.5 \%)$. The dataset contained no missing data.

\section{Measures (Sample \#4)}

We measured multidimensional career insecurity with the above preselected 63 German career insecurity items. The participants indicated the extent to which they agreed with the items on a five-point Likert-type scale ranging from 1 (totally disagree) to 5 (totally agree). The items were grouped in their respective dimensions. The order of the items within the dimension was fully randomized, as was the order of the dimensions.

For use in later parts of the manuscript (Study 2, Part 3), we measured quantitative job insecurity (threat of losing one's job) with the four-item scale developed by De Witte (2000) and validated by Vander Elst et al. (2014). A sample item is "I think I might lose my job in the near future." Qualitative job insecurity (threat of losing different aspects of one's job) was measured with the four-item scale (e.g., "I feel that the organization can provide me with stimulating job content in the near future [R]") of Hellgren et al. (1999). The respondents were asked to rate all quantitative and qualitative job insecurity items on a five-point Likert-type scale ( $1=$ strongly disagree to $5=$ strongly agree). We measured perceived low employability using a scale from De Cuyper et al. (2011). The scale consists of four statements (e.g., "Given my qualifications and experience, getting a new job would not be very hard at all"), with a seven-point Likert-type scale ranging from 1 (totally disagree) to 7 (totally agree). Because the scale originally measures perceived employability, we recoded the values associated with the responses prior to our data analyses to represent low employability perceptions. We measured perceived career barriers with Hirschi and Freund's (2014) six-item scale. The respondents had to indicate on a six-point Likert-type scale ranging from 1 (totally disagree) to 6 (totally agree) the extent to which different factors (e.g., external circumstances, family responsibilities) act as barriers to their career development. Furthermore, we applied one-dimensional career insecurity scales from Colakoglu (2011) and Höge et al. (2012). Colakoglu's (2011) scale consists of five items. Responses were given on a five-point Likert-type scale ranging from 1 (strongly disagree) to 5 (strongly agree). A sample item is "I will not be able to get jobs easily with other employers." One-dimensional career insecurity as conceptualized by Höge et al. (2012) was measured with four items on a six-point Likert-type scale ranging from 1 (totally disagree) to 6 (totally agree). A sample item is "I am not sure whether I shall achieve my career aims."

\section{Data analysis}

We applied an EFA (PROMAX rotation) without fixing the numbers of expected factors and using principal axis factors extraction, as recommended by Hinkin (1998), to the 63 career insecurity items. Based on the factor eigenvalues, the expected eight-factor solution emerged (eigenvalues between 1.62 and 27.82, together explaining $76.70 \%$ of the total variance). Within the rotated factor solution, all items had their highest loading on the theoretically expected factor. The factor loadings ranged from .51 to .96 , and there were no cross-loadings above .40 . The factor intercorrelations ranged from .30 to .70 (i.e., eight dimensions that are moderately positively related).

Based on these results, the final item selection was conducted by applying different criteria. First, the item selection should ascertain that the dimension is represented in its full scope. Consequently, items that cover a new facet of the dimension-in comparison to another item with a higher factor loading, but an already represented facet-were preferred (Hinkin, 1995). Second, following a conservative approach (Peterson, 2000), each selected item should also have a factor loading higher than .70, clearly exceeding the recommended minimum cutoff value of .40 (Ford et al., 1986 ; Hinkin, 1998). Third, as a subordinate selection criterion, at least one item from the cognitive and affective career insecurity component was retained. By accounting for these criteria, we aimed to select items that reflect the dimension in its entire scope and show high reliability values. Table 2 shows factor loadings, means, standard deviations, corrected item-total correlations, and Cronbach's alphas for the subscales (32 items in total, four items per dimension) of the $\mathrm{MU}-\mathrm{Cl}-\mathrm{S}^{4}$ that were retained for use in subsequent studies. 
TAB LE 2 Career insecurity items and related statistics in sample \#4 (Study 2, EFA)

\begin{tabular}{|c|c|c|c|c|c|}
\hline Item & $\begin{array}{l}\text { Introduction sentence: Please indicate to what extent } \\
\text { you agree to the following statements, if you think } \\
\text { about your future career. }\end{array}$ & $\begin{array}{l}\text { Factor } \\
\text { Loading EFA }\end{array}$ & M & $S D$ & $r_{\text {it }}$ \\
\hline \multicolumn{6}{|c|}{ Cl-Career opportunities (.92) } \\
\hline 1 & $\begin{array}{l}\text { I am anxious that in my future career, no promotion } \\
\text { possibilities could arise. }\end{array}$ & .91 & 2.65 & 1.13 & .80 \\
\hline 2 & $\begin{array}{l}\text { I am worried that the career opportunities in my } \\
\text { occupational field could develop unfavorably. }\end{array}$ & .86 & 2.65 & 1.11 & .83 \\
\hline 3 & $\begin{array}{l}\text { I am worried that I might not get opportunities to take } \\
\text { over occupational responsibilities in the future. }\end{array}$ & .81 & 2.53 & 1.12 & .80 \\
\hline 4 & $\begin{array}{l}\text { Chances are, my set career might not provide desired } \\
\text { opportunities for further development. }\end{array}$ & .85 & 2.77 & 1.17 & .81 \\
\hline \multicolumn{6}{|c|}{$\mathrm{Cl}$-Decreased prestige \& qualification requirements of future employment (.91) } \\
\hline 5 & $\begin{array}{l}\text { I fear that I might pursue a work with low prestige in } \\
\text { the future. }\end{array}$ & .90 & 2.27 & 1.13 & .79 \\
\hline 6 & $\begin{array}{l}\text { I wonder if the future qualification requirements of my } \\
\text { employment situation could be less. }\end{array}$ & .79 & 2.36 & 1.06 & .80 \\
\hline 7 & $\begin{array}{l}\text { I am anxious that the prestige of my future employment } \\
\text { could decrease. }\end{array}$ & .90 & 2.39 & 1.12 & .83 \\
\hline 8 & $\begin{array}{l}\text { I am worried that the professional aspiration level of } \\
\text { my work deteriorates. }\end{array}$ & .74 & 2.47 & 1.16 & .79 \\
\hline \multicolumn{6}{|c|}{$\mathrm{Cl}$-Contractual employment conditions (.92) } \\
\hline 9 & I wonder if my salary could develop undesirably. & .86 & 2.79 & 1.17 & .76 \\
\hline 10 & $\begin{array}{l}\text { I am worried that the contractual framework of my } \\
\text { future work could change unfavorably. }\end{array}$ & .81 & 2.83 & 1.19 & .82 \\
\hline 11 & $\begin{array}{l}\text { I fear that I might have to conduct my future work } \\
\text { under worse conditions (e.g., working hours, salary). }\end{array}$ & .81 & 2.76 & 1.17 & .83 \\
\hline 12 & $\begin{array}{l}\text { I wonder if my future contractual working conditions } \\
\text { might worsen. }\end{array}$ & .72 & 2.83 & 1.14 & .81 \\
\hline \multicolumn{6}{|c|}{$\mathrm{Cl}$-Unemployment (.96) } \\
\hline 13 & $\begin{array}{l}\text { I fear that I might be unemployed at some point in the } \\
\text { future. }\end{array}$ & .91 & 2.56 & 1.22 & .91 \\
\hline 14 & I am worried that I could be unemployed in my career. & .91 & 2.58 & 1.24 & .90 \\
\hline 15 & I wonder if I could be unemployed in my future career. & .92 & 2.61 & 1.24 & .90 \\
\hline 16 & $\begin{array}{l}\text { I am worried that I might be affected by a dismissal } \\
\text { during my career. }\end{array}$ & .89 & 2.58 & 1.23 & .89 \\
\hline \multicolumn{6}{|c|}{$\mathrm{Cl}$-Change of workplace (.92) } \\
\hline 17 & $\begin{array}{l}\text { I fear that I might have to involuntarily work for } \\
\text { another employer in the future. }\end{array}$ & .96 & 2.49 & 1.17 & .83 \\
\hline 18 & $\begin{array}{l}\text { I am worried that I involuntarily have to change to an } \\
\text { employment outside of my current organization }\end{array}$ & .95 & 2.49 & 1.18 & .83 \\
\hline
\end{tabular}


TABLE 2 (Continued)

\begin{tabular}{|c|c|c|c|c|c|}
\hline Item & $\begin{array}{l}\text { Introduction sentence: Please indicate to what extent } \\
\text { you agree to the following statements, if you think } \\
\text { about your future career. }\end{array}$ & $\begin{array}{l}\text { Factor } \\
\text { Loading EFA }\end{array}$ & M & $S D$ & $r_{\text {it }}$ \\
\hline 19 & $\begin{array}{l}\text { I am worried that the future could bring along an } \\
\text { unwanted transition of my work. }\end{array}$ & .80 & 2.68 & 1.19 & .81 \\
\hline 20 & $\begin{array}{l}\text { I wonder if I might have to involuntarily change my } \\
\text { occupation in my future career. }\end{array}$ & .71 & 2.49 & 1.15 & .80 \\
\hline \multicolumn{6}{|c|}{ Cl-Retirement (.91) } \\
\hline 21 & $\begin{array}{l}\text { I wonder if the level of pension payments could develop } \\
\text { in an undesired manner. }\end{array}$ & .88 & 3.76 & 1.11 & .82 \\
\hline 22 & $\begin{array}{l}\text { I fear that the conditions for my retirement could } \\
\text { worsen. }\end{array}$ & .85 & 3.69 & 1.18 & .80 \\
\hline 23 & $\begin{array}{l}\text { I wonder if my retirement age could increase } \\
\text { undesirably. }\end{array}$ & .87 & 3.74 & 1.20 & .78 \\
\hline 24 & $\begin{array}{l}\text { Chances are, my transition from work to retirement } \\
\text { might be more unfavorable than expected. }\end{array}$ & .83 & 3.58 & 1.11 & .80 \\
\hline \multicolumn{6}{|c|}{ Cl-Work-nonwork interactions (.92) } \\
\hline 25 & $\begin{array}{l}\text { I wonder if my family and my career could be } \\
\text { incompatible in the future. }\end{array}$ & .95 & 2.82 & 1.26 & .79 \\
\hline 26 & $\begin{array}{l}\text { Chances are, the compatibility between work and } \\
\text { private life could be problematic in the future. }\end{array}$ & .93 & 2.90 & 1.16 & .86 \\
\hline 27 & $\begin{array}{l}\text { I wonder if my free time and my work could conflict in } \\
\text { the future. }\end{array}$ & .85 & 2.84 & 1.16 & .79 \\
\hline 28 & $\begin{array}{l}\text { I feel uneasy that my work and my private life could } \\
\text { influence each other undesirably in the future. }\end{array}$ & .82 & 2.82 & 1.14 & .79 \\
\hline \multicolumn{6}{|c|}{ Cl-Discrepancy between individual resources/work demands (.93) } \\
\hline 29 & $\begin{array}{l}\text { Chances are, my physical or mental resources might } \\
\text { once not be sufficient to manage work tasks well. }\end{array}$ & .87 & 2.72 & 1.16 & .81 \\
\hline 30 & $\begin{array}{l}\text { I am anxious that my personal work ability might } \\
\text { deteriorating so much that I can no longer meet } \\
\text { performance requirements. }\end{array}$ & .89 & 2.47 & 1.11 & .85 \\
\hline 31 & $\begin{array}{l}\text { I wonder if I might not any longer be up to the demands } \\
\text { of my work in the future. }\end{array}$ & .86 & 2.49 & 1.06 & .81 \\
\hline 32 & $\begin{array}{l}\text { I am worried that the personal capability in my career } \\
\text { might not be sufficient for the work requirements. }\end{array}$ & .88 & 2.44 & 1.04 & .84 \\
\hline
\end{tabular}

Note. $r_{\text {it }}=$ corrected item-total correlations. Five-point Likert-type scale: (1) totally disagree; (2) rather disagree; (3) neither agree nor disagree; (4) rather agree; (5) totally agree. $N=404$.

To provide further clarity about the fit of the items to the theoretical career insecurity construct and its dimension, we exemplarily describe some items and their conceptual fit. As mentioned above, the general career insecurity construct includes both unsureness (something might/could happen) about the future as well as thoughts (about something undesired) or worries about the future. These aspects were considered in the item formulation. For example, the item "I am worried that the career opportunities in my occupational field could develop unfavorably" from the Cl-Career opportunities dimension clearly includes both conceptual aspects. Moreover, the introduction sentence (see Table 2) and the items were formulated to include the mid- and long-term future and both intra- and extra-organizational career aspects (e.g., "I am worried that the contractual framework of my future work could change unfavorably" from 
the $\mathrm{Cl}$-Contractual employment condition dimension, or "I wonder if I could be unemployed in my future career" from the $\mathrm{Cl}$-Unemployment dimension).

\subsection{Part 2: Confirmation of factor structure and model comparisons}

To confirm the results regarding the 32 items obtained by the EFA with confirmatory factor analysis (CFA), we collected a further independent sample.

\subsubsection{Sample and procedure (Sample \#5)}

Participants were recruited through another German online-access research panel company in 2019. The respondents received a small incentive (i.e., 2.50 Euros, approx. 3 U.S. dollars) for participating in the study. Based on data quality checks (cf. approach used in Sample \#4), 7.56\% of the participants were excluded, resulting in a final sample size of 1091 (51.5\% men). The respondents were $M=44.11$ years old $(S D=12.74)$, came from a large variety of German industry sectors, and $66.09 \%$ had full-time employment, and about one-third held a university degree (37.0\%). The dataset contained no missing data.

\subsection{2 | Measures (Sample \#5)}

We measured multidimensional career insecurity (32 items, final version), quantitative job insecurity, qualitative job insecurity, perceived low employability, perceived career barriers, and one-dimensional career insecurity with the same scales as in Sample \#4.

Regarding further measures that will be used in the following sections of the manuscript, we measured neuroticism using four items of the German version of the BFI-K (Rammstedt \& John, 2005). The respondents were asked to rate the items on a five-point Likert-type scale from 1 (strongly disagree) to 5 (strongly agree). A sample item is "I see myself as someone who gets nervous easily." We measured the frequency of physical symptoms within the last three months with five items from Pennebaker (1982), including headache, muscle tension, and sleep disturbances, on a five-point Likert-type scale ranging from 1 (very seldom) to 5 (very often). Furthermore, we measured burnout exhaustion with the Oldenburg Burnout Inventory (OLBI; Demerouti et al., 2003). The respondents were asked to rate eight items on a six-point Likert-type scale ranging from 1 (strongly disagree) to 6 (strongly agree). A sample item is "After my work, I regularly feel worn out and weary." We measured in-role behavior (job performance) with seven items developed by Williams and Anderson (1991). A sample item is "I meet the formal requirements of my job." The participants answered on a five-point Likert-type scale ranging from 1 (totally disagree) to 5 (totally agree). Counterproductive work behavior was measured with a scale from Spector et al. (2010). The participants were asked to answer ten items related to how often they have done different things in their present job ( 1 = never, 2 = once or twice, $3=$ once or twice/month, 4 once or twice/week, and 5 = every day). Sample items are "Purposely wasted your employer's materials/supplies" and "Insulted or made fun of someone at work." We measured career satisfaction with a German version (Spurk et al., 2011) of the career satisfaction scale developed by Greenhaus et al. (1990). To measure job satisfaction in an economic and appropriate way (Wanous et al., 1997), we used a single item measure ("I am satisfied with my current job"). The participants answered on a five-point Likert-type scale ranging from 1 (totally disagree) to 5 (totally agree). Affective career commitment was measured with six items (Meyer et al., 1993). A sample item is "My occupation is important to my self-image." The respondents were asked to rate these items on a seven-point Likert-type scale ranging from 1 (strongly disagree) to 7 (strongly agree). We measured career turnover intentions with a three-item scale (Barthauer et al., 
2020). A sample item is "I often think of giving up my current professional career." The respondents were asked to rate these items on a seven-point Likert-type scale ranging from 1 (strongly disagree) to 6 (strongly agree).

\subsection{3 | Data analysis}

We conducted CFA with the 32 career insecurity items of the MU-Cl-S to confirm the eight-factor solution of the new scale using Mplus Version 8.1 (Muthén \& Muthén, 1998-2015). We evaluated the model fit based on different model fit indices: comparative fit index (CFI; Kline, 2011), standardized root mean square residual (SRMR; Hu \& Bentler, 1998), and the root mean square error of approximation (RMSEA; Kline, 2011). Models with a CFI value greater than .95 and RMSEA and SRMR values less than .08 indicate a good model fit (Hu \& Bentler, 1998).

We tested and compared one theoretically plausible model, Model 1 (eight intercorrelated latent first-order factors), with another theoretically plausible model, Model 2 (eight latent first-order factors loading on one latent secondorder general career insecurity factor). Model 2 assumes that a latent general career insecurity factor accounts for the correlational pattern between the first-order factors. Such a model has specific advantages because it, for example, accounts for the relationships between the eight career insecurity dimensions in a more parsimonious way (second-order models have more degrees of freedom than first-order models with correlated factors; Byrne, 2005). Finally, Model 1 and Model 2 were compared with Model 3 (general factor model: all 32 items loading on one latent first-order factor; $\left.\chi^{2}[464]=13242.48, p<.001, \mathrm{CFI}=.58, \mathrm{RMSEA}=.16, \mathrm{SRMR}=.10\right)$. Model comparisons showed that Model $1\left(\Delta \chi^{2}=11458.27, \Delta d f=28, p<.001, \Delta \mathrm{CFI}=.38\right)$ and Model $2\left(\Delta \chi^{2}=11086.60, \Delta d f=8, p<.001, \Delta \mathrm{CFI}=.37\right)$ were preferable in terms of model fit compared to Model 3. Model 1 showed a better model fit compared to Model 2 when considering the Chi-square difference test $\left(\Delta \chi^{2}=371.66, \Delta d f=20, p<.001\right)$, but not when considering the $\Delta C F I$ of .01, which should be greater than .01 to indicate meaningful differences (Cheung \& Rensvold, 2002). Both Model $1\left(\chi^{2}[436]=1784.21, p<.001 ; \mathrm{CFI}=.96, \mathrm{RMSEA}=.05, \mathrm{SRMR}=.04\right)$ and Model $2\left(\chi^{2}[456]=2155.87, p<.001\right.$; $\mathrm{CFI}=.95, \mathrm{RMSEA}=.06, \mathrm{SRMR}=.06$ ) showed good overall model fit. Moreover, Model 2 showed a high composite reliability of .92, indicating that the eight dimensions consistently measure the second-order career insecurity factor (Colwell, 2016; Raykov, 1997). Furthermore, these results were replicated in Samples \#6 and \#7 (see Online Supplements: Tables S6).

In sum, these results suggest that (a) the eight-factor solution from the EFA in Sample \#4 can be confirmed with a CFA across three independent samples; (b) an eight-factor solution fits the data better than a one-factor solution across three independent samples; and (c) the shared variance of the eight correlated factors can parsimoniously be explained by a latent second-order general career insecurity factor across three independent samples. Altogether, these results suggest that the scale can be either applied by investigating overall career insecurity or as eight single career insecurity factors, reflecting the intercorrelated single career insecurity dimensions and their specific content.

\section{3 | Part 3: Construct validity: Discriminant and convergent validity in relation to similar constructs and one-dimensional career insecurity measures (Sample \#4 and \#5)}

After confirming the structure of the MU-Cl-S, we used Sample \#4 (see above, Study 2, Part 1, N=404) and Sample \#5 (see above, Study 2, Part 2, $N=1091$ ) to conduct further validation analyses. The first goal of these analyses was to show convergent and discriminant validity regarding similar constructs discussed in Study, Part 1 (i.e., job insecurity, perceived low employability, perceived career barriers) and one-dimensional career insecurity scales (Colakoglu, 2011; Höge et al., 2012). As argued in Study 1, the developed career insecurity construct is conceptually related to yet distinct from similar constructs, resulting in the following hypotheses: 
Hypothesis 1: The MU-Cl-S can be discriminated from (a) job insecurity; (b) perceived low employability; (c) perceived career barriers; and (d) one-dimensional career insecurity.

Hypothesis 2: The MU-Cl-S is positively related to (a) job insecurity; (b) perceived low employability; (c) perceived career barriers; and (d) one-dimensional career insecurity.

\subsection{1 | Discriminant validity}

To test the discriminant validity of the eight career insecurity dimensions of the $\mathrm{MU}-\mathrm{Cl}-\mathrm{S}$, we used two frequently applied approaches: CFA model comparisons and related Chi-square difference tests and the Fornell-Larcker (1981) test.

\section{CFA model comparisons}

These comparisons always included one of the eight career insecurity dimensions and one of the similar constructs (e.g., job insecurity, perceived low employability, or one-dimensional career insecurity). Moreover, we always compared two different CFA models with each other. Model A was a one-factor model, whereas Model B was a two-factor model. Within Model A, four items of the specific career insecurity dimension of the $\mathrm{MU}-\mathrm{Cl}-\mathrm{S}$ (e.g., $\mathrm{Cl}$-Retirement) and all items of one of the similar constructs (e.g., quantitative job insecurity) were modeled as one latent first-order factor. Model B was a latent two-factor measurement model (e.g., Cl-Retirement and job insecurity modeled as two separate, but intercorrelated, latent first-order factors). According to Hypothesis 1, a two-factor model (i.e., Model B) should show a significantly better model fit than a one-factor model (i.e., Model A). As expected, in all conducted comparisons with both samples (see Online Supplements: Tables S7.1 to Table S7.6), the two-factor model (i.e., Model B) was preferable to the one-factor model (i.e., Model A; Sample \#4: $\Delta \chi^{2}$ ranged from 253.96 to $1057.69, \Delta d f=1$, all $p$-values below .001; Sample \#5: $\Delta \chi^{2}$ ranged from 588.07 to $2825.79, \Delta d f=1$, all $p$-values below .001).

\section{Fornell-Larcker (1981) test}

Furthermore, we conducted the Fornell-Larcker (1981) test, which examines the average variance extracted (AVE) of the factor indicators by its underlying latent construct. A latent construct (e.g., one career insecurity dimension) should explain more variance in its own indicators than in other constructs (e.g., quantitative job insecurity). Moreover, the AVE should be larger than .50 to show that the latent construct explains more variance in its indicators compared to measurement error. In all Fornell-Larcker tests using Samples \#4 and \#5, the AVE of all eight career insecurity dimensions was above .50 (.72-.86 and .64-.85, respectively). In all cases in both samples, these AVE values exceeded the squared correlations of the dimensions with similar constructs (i.e., job insecurity, perceived employability, perceived career barriers) or the one-dimensional career insecurity measures (squared correlations ranged between .01 and .61 in Sample \#4 and between .00 and .53 in Sample \#5), supporting the discriminant validity of all eight insecurity dimensions. Taken together, the results from the CFA model comparisons and the Fornell-Larcker test support Hypothesis 1.

\subsection{2 | Convergent validity}

Table 3 presents the correlations of the MU-Cl-S and its eight dimensions with similar constructs and one-dimensional career insecurity measures in Sample \#4 and Sample \#5. MU-Cl-S and all eight career insecurity dimensions werewith one exception-significantly positively correlated (with varying size) with similar constructs and one-dimensional career insecurity scales ( $r$ ranged from $.10[p=.048]$ to $.78[p<.001]$ in Sample \#4; and from $.01[p=.755]$ to .73 $[p<.001]$ in Sample \#5). The only non-significant correlation was found in Sample \#5 between perceived low employability and $\mathrm{Cl}$-Work-nonwork interactions $(r=.01, p=.755)$. In sum, these results support Hypothesis 2. 


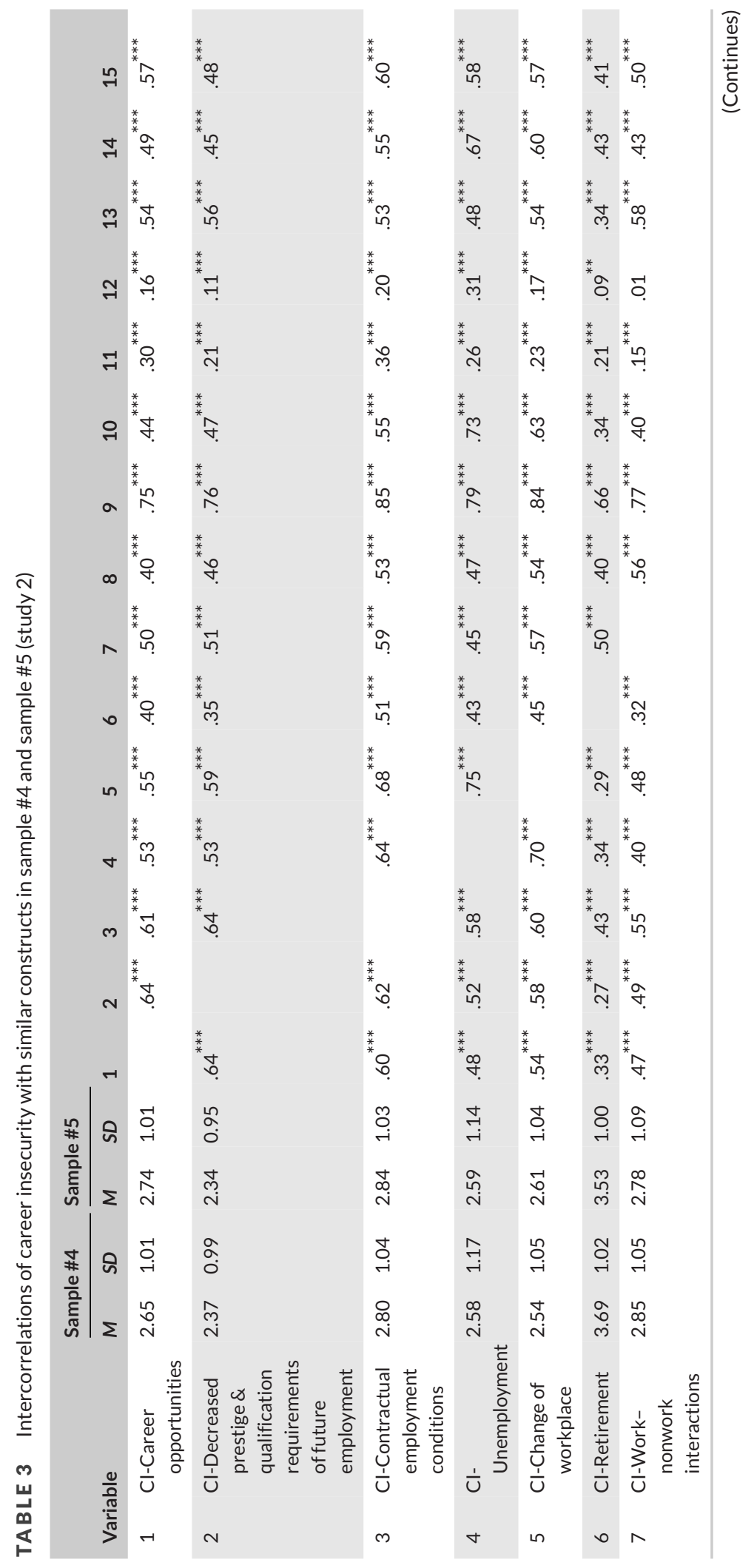




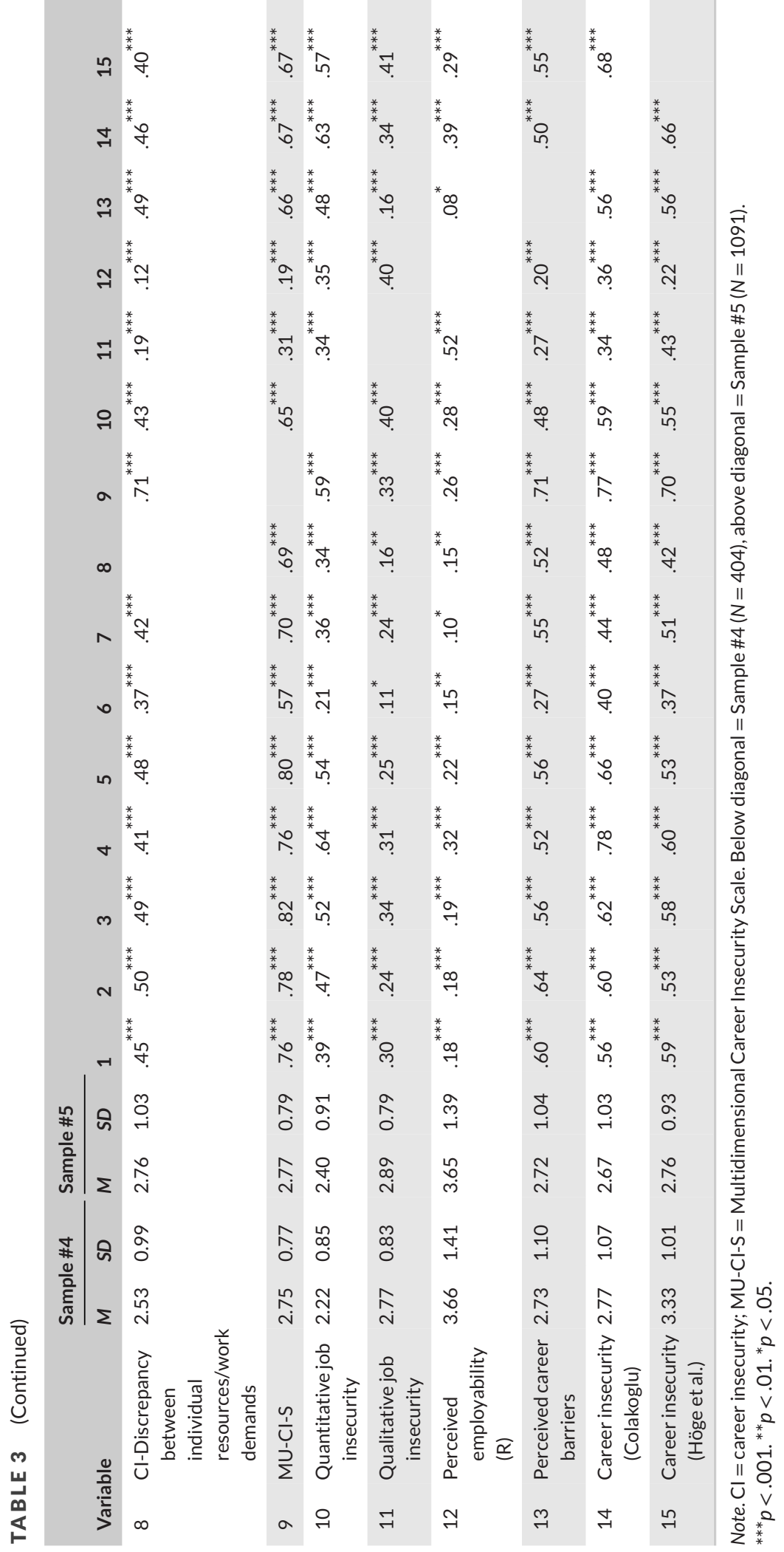




\section{4 | Discussion study 2}

Based on the results of Study 1, we developed a comprehensive, psychometrically sound, and multidimensional measurement tool (i.e., the MU-Cl-S). The eight career insecurity dimensions can be economically measured with four items per dimension. The initial analyses revealed that the $\mathrm{MU}-\mathrm{Cl}-\mathrm{S}$ has construct validity (i.e., factorial, discriminant, and convergent validity). Furthermore, the $\mathrm{MU}-\mathrm{Cl}$-S can either be applied as an overall mean score representing career insecurity in its entire breadth (as shown by an adequate CFA model with a general career insecurity second-order factor and high composite reliabilities across three independent samples) or as single dimensions representing specific aspects of career insecurity. The MU-Cl-S is empirically different from quantitative and qualitative job insecurity, perceived low employability, perceived career barriers, and one-dimensional career insecurity measures. Moreover, quantitative job insecurity and one-dimensional career insecurity seem to specifically tap into the career insecurity dimension of unemployment, which can be seen in the relatively high correlations in Table 3, indicating the need for a broader career insecurity construct. Finally, the varying correlation sizes of the eight separate career insecurity dimensions of the MU-Cl-S among each other and with the similar analyzed constructs suggest that a content-specific investigation of career insecurity provides a useful perspective for future insecurity research.

\section{4 | STUDY 3: CRITERION VALIDITY - RELATIONS WITH CENTRAL OUTCOMES AND INCREMENTAL VALIDITY BEYOND OTHER INSECURITY MEASURES}

In this stage of scale development, it is important to show that the newly developed career insecurity scale exhibits meaningful relationships with theoretically relevant outcomes (i.e., health/well-being, job performance, career success, and career attitudes) and can explain additional variance in these variables beyond other existing insecurity measures (Hinkin, 1995; Wright et al., 2017). We will derive a series of hypotheses based on stress (Folkman et al., 1986; Hobfoll et al., 2018) and social-cognitive career frameworks (Lent \& Brown, 2013), which we will test in one crosssectional and one time-lagged sample. In terms of conceptual fit and integration, we decided to explain the relationships of career insecurity with health and well-being and job performance by stress approaches, and the relationships with career success and career attitudes by social-cognitive career frameworks. We intentionally use two theoretical approaches to show that the construct career insecurity contains aspects of both experienced stress (e.g., thoughts and worries, insecurity) and career development (e.g., different content domains of the future career).

Theoretical approaches to stress (e.g., the Conservation of Resource Theory; Hobfoll et al., 2018) assume that stress results when resources are threatened. Career insecurity can be seen as a career-related stressor that represents a threat to resources. For example, a possible loss of income (as one thought and worry of career insecurity) represents a threat to the fundamental monetary resource of money, which is representative of other valuable resources in society (e.g., third-party services, secure home; Hobfoll et al., 2018). A potential loss of prestige or employment (as one thought and worry of career insecurity) represents a threat to social relationships and social embedment, which are fundamental needs of individuals (Hobfoll et al., 2018). As a final example, potentially increased work-nonwork conflict (as one thought and worry of career insecurity) represents a threat to belongingness, support, and family commodities in terms of material resources.

These threats resulting from career insecurity are associated with strain and associated negative outcomes (Hobfoll et al., 2018), such as reduced health and well-being, as shown in increased physical symptoms or burnout exhaustion (Hobfoll et al., 2018; Shoss, 2017). Moreover, strain typically hinders optimal functioning toward achieving personal and organizational goals because strain narrows attention and diminishes self-regulation, such as allocating effort or monitoring behavior (Ortlieb \& Weiss, 2018; Shoss, 2017; Sverke et al., 2002). Therefore, career insecurity should be associated with lowered levels of job performance (e.g., reduced in-role behavior) or increased levels of counterproductive work behavior (Hobfoll et al., 2018; Shoss, 2017). Past empirical research in other insecurity domains supports this reasoning by showing that job insecurity is negatively related to health, job performance, and 
different satisfaction judgments (Cheng \& Chan, 2008; De Witte et al., 2016; Shoss, 2017; Sverke et al., 2019). Furthermore, one-dimensional career insecurity showed negative correlations with general well-being (Höge et al., 2012) and job performance (Ortlieb \& Weiss, 2018). Overall, based on stress approaches and past research, we assume detrimental effects of career insecurity on health and well-being (see Hypothesis 3 ) and job performance (see Hypothesis 4) outcomes.

Hypothesis 3: Career insecurity is positively related to (a) physical symptoms and (b) burnout exhaustion.

Hypothesis 4: Career insecurity is (a) negatively related to in-role behavior and (b) positively related to counterproductive work behavior.

Social-cognitive career management (e.g., Lent \& Brown, 2013) is another suitable theoretical approach for understanding the outcomes of career insecurity. One core idea of social-cognitive reasoning is that agency and control are important drivers of successful career development (Bandura, 1986; Shoss, 2017; Sverke et al., 2002). For example, career-related self-efficacy and outcome expectancy both assume a sense of agency and control that is lacking when individuals perceive their career as insecure. An individual who thinks and worries that his or her future career might develop in an undesired manner also experiences a lack of agency and control because it is unclear how to affect and manage the future and what his or her future career might look like. Moreover, such a lack of control is accompanied with negative arousal, which is also detrimental to career management (Bandura, 1986; Lent \& Brown, 2013).

Accordingly, career insecurity should be negatively related to career success, such as workplace status (Abele \& Spurk, 2009; Ng et al., 2005) and job and career satisfaction (Abele \& Spurk, 2009). Career satisfaction is an individual's evaluation of his or her career until now. It makes sense to assume that a current career insecurity evaluation (thoughts and worries about the future career) might be negatively related to the evaluation of the progression from the past to present career because the road to the present career might be seen as one reason for the present insecure situation. Hence, it might be that individuals with higher career insecurity are attributing this insecurity to their past career decisions and development, which relates to lower career satisfaction judgements compared to individuals with lower career insecurity.

Moreover, lower career management and lower career success (e.g., job and career satisfaction) are associated with career attitudes like lower career commitment or higher career turnover intentions (Spurk et al., 2019; Zhu et al., 2020). Career turnover intentions are defined as an individual's attitude toward and perceived probability of staying in or leaving a profession or a chosen career track (e.g., career as a specialist in a current occupational field; Aydogdu \& Asikgil, 2011; Barthauer et al., 2020). Because career insecurity might be interpreted as failure and that the career may be developing in an undesired direction, individuals with higher levels of career insecurity might also show higher career turnover intentions (Barthauer et al., 2020; Lent \& Brown, 2013; Luzzo, 1993).

Past empirical research in other insecurity domains provides support for our assumptions. For example, job insecurity is negatively related to job satisfaction and attitudes, such as commitment (Shoss, 2017; Sverke et al., 2002). Furthermore, one-dimensional career insecurity showed negative correlations with career success (Colakoglu, 2011; Spurk et al., 2016). In sum, based on reasoning from social-cognitive career models and past research, we assume that there is a detrimental relationship between career insecurity and career success (see Hypothesis 5) and career attitudes (see Hypothesis 6).

Hypothesis 5: Career insecurity is negatively related to (a) career satisfaction and (b) job satisfaction.

Hypothesis 6: Career insecurity is (a) negatively related to career commitment and (b) positively related to career turnover intentions.

Additionally, career insecurity should show incremental validity beyond job insecurity when predicting career outcomes because the content domain of career insecurity covers the career whereas the content domain of job insecurity covers the current job or employment. Moreover, because career and job insecurity are related to partly 
different threats, a unique and different stress experience should result from career insecurity. Therefore, career insecurity should also show incremental validity when predicting strain-related outcomes in the form of health and well-being and job performance. Finally, because the conceptualization of career insecurity applied here and the developed scale are different and broader compared to other one-dimensional career insecurity and job insecurity measures, and because we already established discriminant validity against these other insecurity constructs (see Study 2 ), we hypothesize the following:

Hypothesis 7: The MU-Cl-S explains variance in (a) physical symptoms; (b) burnout exhaustion; (c) in-role behavior; (d) counterproductive work behavior; (e) career satisfaction; (f) job satisfaction; (g) career commitment; and (h) career turnover intentions beyond other insecurity constructs (i.e., job insecurity and one-dimensional career insecurity constructs).

\section{1 | Method}

In order to test the abovementioned hypotheses, we used Sample \#5 ( $N=1091$, see Study 2, and Tables S2 and S4). Moreover, we added a time-lagged dataset (Sample \#6), which is described in the following.

\subsubsection{Sample and procedure (Sample \#6)}

Two student assistants collected the sample in two subsequent online survey waves via personal contacts with employees and organizations, with three months between each wave. The participants could take part in a voucher raffle as an incentive. Three vouchers worth 50 Swiss francs (approx. 53.3 U.S. dollars) were raffled at each measurement time point. In addition, three further vouchers, each worth 60 Swiss francs (approx. 64 U.S. dollars), were raffled among all participants who took part at all measurement points. The sample of 182 employees (T1; April/May 2017) in Switzerland included $65.4 \%$ women and $34.6 \%$ men, with a mean age of 42.02 (SD =11.54). On average, the participants worked 36.11 (SD = 7.45) hours per week (57.1\% academics, $42.9 \%$ non-academics). They worked in diverse jobs and were employees of different organizations. The dropout rate was 31.87\% ( $N=124$ at T2; August 2017). The participants who dropped out did not differ from those who participated at both times with regard to insecurity variables (i.e., the MU-Cl-S, job insecurity, one-dimensional career insecurity scales). The analyses are based on the entire sample ( $N=182$ ) because we used Mplus version 8.1 (Muthén \& Muthén, 1998-2015) with a Full Information Maximum Likelihood Estimator to account for the missing data (Graham \& Coffman, 2012).

\subsection{2 | Measures (Sample \#6)}

We measured multidimensional career insecurity at T1 with the $\mathrm{MU}-\mathrm{Cl}-\mathrm{S}$. We measured quantitative job insecurity and one-dimensional career insecurity at T1 with the same scales as in Sample \#4. Additionally, we measured neuroticism at T1 with the same scale as in Sample \#5. All outcomes were measured at T2. We measured the frequency of physical symptoms within the last three months and in-role behavior as described in Sample \#5 (see above). We used a single-item measure regarding overall satisfaction with the career (Heslin, 2003). The item was rated on a five-point Likert-type scale ranging from 1 (totally disagree) to 5 (strongly agree). We measured affective career commitment using a scale developed by Felfe et al. (2006; see also Spurk et al., 2016). The respondents were asked to rate five items on a six-point Likert-type scale ranging from 1 (strongly disagree) to 6 (strongly agree). A sample item is "My career has a great personal significance for me." Cronbach's alphas of all applied scales are shown in Table 4 (Sample \#6) and Table S5 (Sample \#5). 


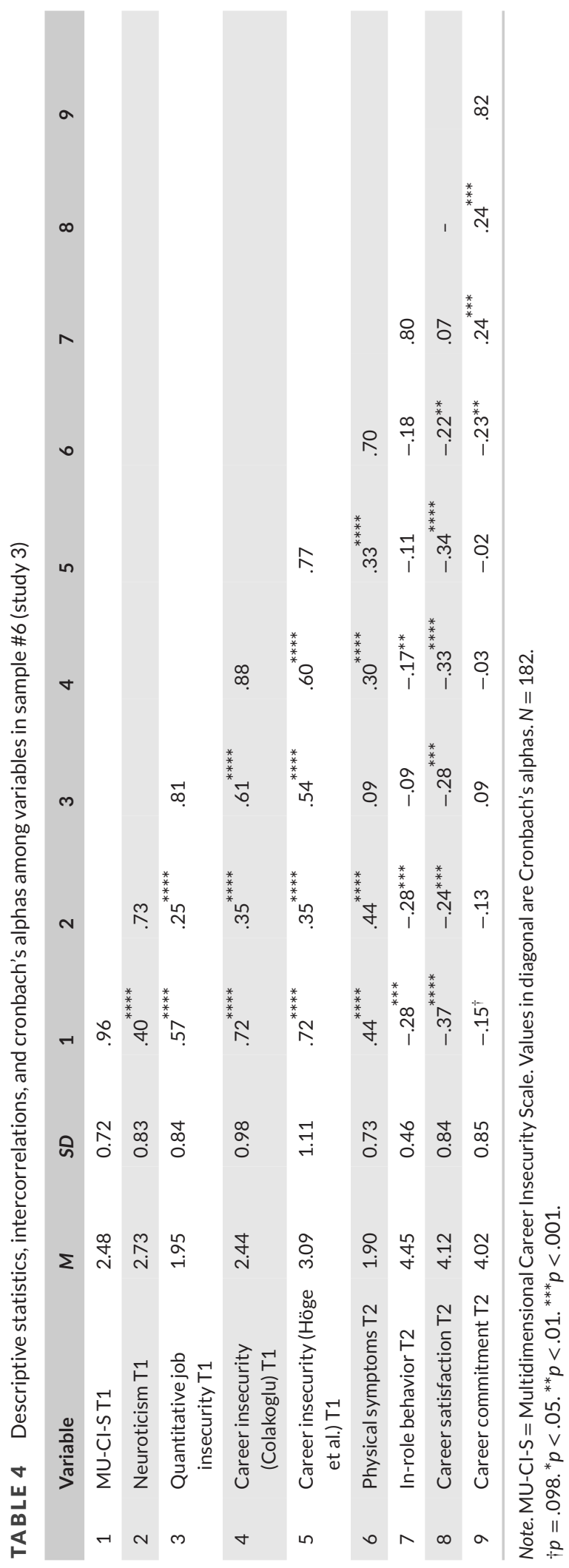




\subsection{3 | Data analysis}

To test the concurrent and predictive validity of the $\mathrm{MU}-\mathrm{Cl}-\mathrm{S}$, we performed bivariate (time-lagged) correlation analyses. To test the incremental validity of the MU-CI-S, we performed a series of multiple hierarchical regression analyses. Because the relationships between career insecurity and its outcomes might be explained by insecure, fearful, and negative affectivity-related personality traits (Mak \& Mueller, 2000; Shoss, 2017), we controlled for neuroticism in the analyses. We regressed each outcome variable (i.e., Sample \#5 + Sample \#6: physical symptoms, in-role behavior, career satisfaction, career commitment; Sample \#5: burnout exhaustion, counterproductive work behavior, job satisfaction, career turnover intentions) on neuroticism in the first step. In the second step, we included quantitative job insecurity, qualitative job insecurity (only in Sample \#5), and both of the one-dimensional career insecurity measures (Colakoglu, 2011; Höge et al., 2012) together. A total of three (Sample \#6) or four (Sample \#5) predictors were added to the model simultaneously in step 2. In the third step, we included the MU-Cl-S to assess whether it significantly explains additional variance in the outcomes, which would show incremental validity. Within the results section, we present the $\Delta R^{2}$ between step 2 and step 3, MU-Cl-S $\beta$ s (within step 3), and the explained variance in step 3 (i.e., $R^{2}$ ). All further details are listed in Table $\mathrm{S} 8$ in the Online Supplements.

\section{2 | Results}

\subsubsection{Concurrent (Sample \#5) and predictive validity (Sample \#6)}

The means, standard deviations, and intercorrelations between the study variables are shown in Table 5 (Sample \#5, first value in parentheses below) and Table 4 (Sample \#6, second value in parentheses below). The MU-Cl-S was positively related to physical symptoms $(r=.46, p<.001 ; r=.44, p<.001)$ and burnout exhaustion $(r=.48, p<.001)$, supporting Hypothesis 3a and 3b.

Moreover, the MU-Cl-S was negatively related to in-role behavior ( $r=-.29, p<.001 ; r=-.28, p=.002)$, supporting Hypothesis 4a, and it was positively related to counterproductive work behavior $(r=.28, p<.001)$, supporting Hypothesis $4 \mathrm{~b}$. The MU-Cl-S was negatively related to career satisfaction $(r=-.41, p<.001 ; r=-.37, p<.001)$ and job satisfaction ( $r=-.42, p<.001$ ), supporting Hypothesis $5 \mathrm{a}$ and $5 \mathrm{~b}$. Additionally, the $\mathrm{MU}-\mathrm{Cl}-\mathrm{S}$ was negatively correlated with career commitment $(r=-.40, p<.001 ; r=-.15, p=.098)$, supporting Hypothesis 6 a. Finally, the MU-CI-S was positively correlated with career turnover intentions $(r=.44, p<.001)$, supporting Hypothesis $6 \mathrm{~b}$.

\subsection{2 | Cross-sectional and time-lagged incremental validity when predicting central outcomes (Sample \#5, Sample \#6)}

Regarding physical symptoms, the MU-Cl-S explained variance beyond all other constructs, with $\Delta R^{2}$ ranging from .03 (Sample \#5, $p<.001$ ) to .09 (Sample \#6, $p<.001$ ). MU-Cl-S $\beta$ s ranged from .28 (Sample \#5, $p<.001$ ) to .43 (Sample \#6, $p=.001$ ). All constructs together (i.e., step 3) explained 32\% (Sample \#6) to 36\% (Sample \#5) of the variance in physical symptoms. In Sample \#5, the MU-Cl-S explained the variance in burnout exhaustion beyond all other constructs $\left(R^{2}=.39, \Delta R^{2}=.03, p<.001 ; \mathrm{MU}-\mathrm{Cl}-\mathrm{S} \beta=.29, p<.001\right)$.

Regarding in-role behavior, the MU-Cl-S explained variance beyond all other constructs, and $\Delta R^{2}$ ranged from .01 (Sample \#5, $p<.001$ ) to .06 (Sample \#6, $p=.001$ ). MU-Cl-S $\beta$ s ranged from -.17 (Sample \#5, $p<.001$ ) to -.39 (Sample \#6, $p=.012$ ). All constructs together explained between $11 \%$ and $13 \%$ of the variance in in-role behavior. Additionally, in Sample \#5, the MU-Cl-S explained the variance in counterproductive work behavior beyond all other constructs $\left(R^{2}=.11, \Delta R^{2}=.02, p<.001 ; \mathrm{MU}-\mathrm{Cl}-\mathrm{S} \beta=.22, p<.001\right)$.

Regarding career satisfaction, the MU-Cl-S explained the variance within Sample \#5 beyond all other constructs $\left(R^{2}=.35, \Delta R^{2}=.01, p<.001 ; \mathrm{MU}-\mathrm{Cl}-\mathrm{S} \beta=-.13, p=.001\right)$. The MU-Cl-S did not explain the variance within Sample \#6 beyond all other constructs $\left(R^{2}=.16, \Delta R^{2}=.02, p=.077\right.$; MU-CI-S $\left.\beta=-.17, p=.269\right)$. However, all other predic- 


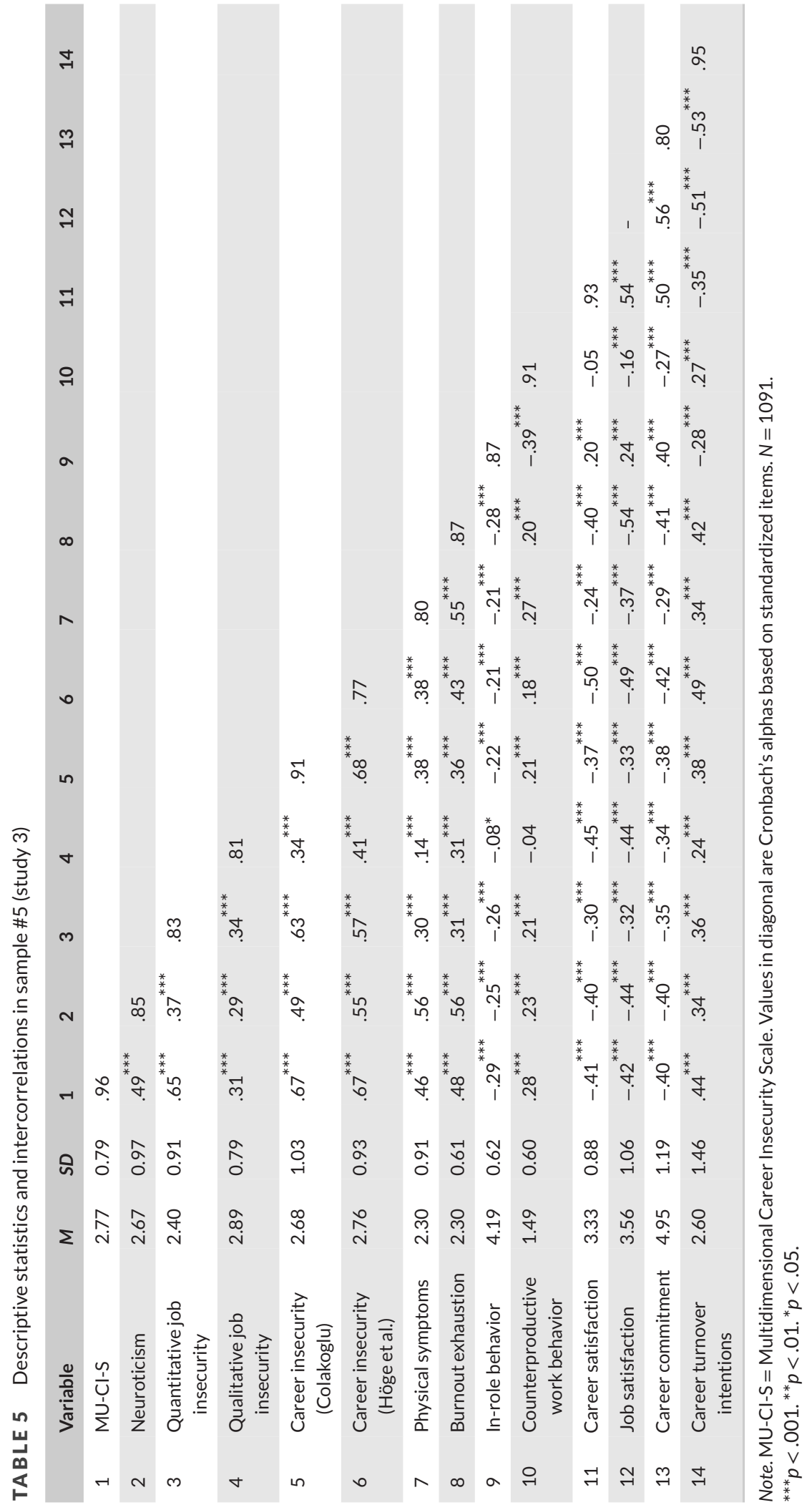


tors also showed nonsignificant results in Sample \#6. Regarding job satisfaction, the $\mathrm{MU}-\mathrm{Cl}-\mathrm{S}$ explained the variance beyond all other constructs within Sample \#5 $\left(R^{2}=.36, \Delta R^{2}=.01, p<.001 ; \mathrm{MU}-\mathrm{Cl}-\mathrm{S} \beta=-.16, p<.001\right)$.

The MU-Cl-S explained the variance in career commitment beyond all other constructs, and $\Delta R^{2}$ ranged from 01 (Sample \#5, $p=.006$ ) to .06 (Sample \#6, $p=.001$ ). MU-Cl-S $\beta$ s ranged from -.11 (Sample \#5, $p=.006$ ) to -.39 (Sample \#6, $p=.016$ ). All constructs together explained between 9\% (Sample \#6) and 26\% (Sample \#5) of the variance in career commitment. Moreover, within Sample \#5, the $\mathrm{MU}-\mathrm{Cl}-\mathrm{S}$ explained the variance in career turnover intention beyond all other constructs $\left(R^{2}=.27, \Delta R^{2}=.01, p<.001\right.$; MU-CI-S $\left.\beta=.17, p<.001\right)$. Overall, these results suggest that the $\mathrm{MU}-\mathrm{Cl}-\mathrm{S}$ has incremental validity beyond neuroticism, quantitative and qualitative job insecurity, and onedimensional career insecurity, supporting Hypothesis 7.

\section{3 $\quad$ Discussion study 3}

In Study 3, we investigated central outcomes of career insecurity derived from stress and social-cognitive career models, which extended the understanding of the relationships between career insecurity and other variables. The results from two independent samples demonstrated the concurrent validity, predictive validity, and cross-sectional and timelagged incremental validity of the $\mathrm{MU}-\mathrm{Cl}-\mathrm{S}$ beyond neuroticism and other insecurity constructs when explaining the variance in poor health and well-being, low job performance, low career success, and low career attitudes related to career management. Given the replication of results across samples, the results are likely robust. In sum, overall career insecurity (represented by the mean score of eight dimensions) seems to have mainly detrimental effects on personal and work-related functioning. Taken together, it appears that the $\mathrm{MU}-\mathrm{Cl}-\mathrm{S}$ has acceptable criterion validity.

\section{I STUDY 4: THE RELATIVE IMPORTANCE OF DIFFERENT CAREER INSECURITY DIMENSIONS}

The goal of Study 4 was to analyze the relative importance of the eight career insecurity dimensions for the relationships with the outcomes used in Study 3 in a large sample of employees using a relative weights analysis. Moreover, we added another indicator of career success as a further outcome (i.e., workplace status as an employee's relative standing in an organization, as characterized by the respect, prominence, and prestige they possess in the eyes of other organizational members; Djurdjevic et al., 2017).

We assume that the career insecurity dimensions will show differing importance when predicting outcomes (e.g., one career insecurity dimension explains more variance in the outcome compared to another career insecurity dimension for the same outcome). Although the eight dimensions share a common core insecurity, they nonetheless reflect unique insecurity aspects that are expressed in diverse future-related thoughts and worries that have already been discriminated in Studies 1 to 3.

For example, the career insecurity dimensions of work-nonwork interactions and discrepancy between individual resources and work demands might explain larger portions of the variance in the outcomes of well-being and health compared to the other dimensions. This assumption is based on research showing that work-nonwork or nonworkwork conflicts especially affect more generic well-being aspects, for instance, overall life satisfaction (Adams et al., 1996) or physical well-being (Kinnunen et al., 2004). Moreover, a potential future misfit of individual resources and work demands can be seen as a lack of personal resources, which has been shown to be relatively strongly related to lower well-being (Hobfoll et al., 2018).

Moreover, the career insecurity dimensions of career opportunities, decreased prestige \& qualification requirements of the future employment, and unemployment might explain relatively large portions of the variance in the outcome of career success compared to the other dimensions. This might be because perceptions of and having appropriate career opportunities are relatively strongly related to career success (Hirschi et al., 2018; Kraimer et al., 2011; Ng 
\& Feldman, 2014a). Moreover, employment prestige and unemployment are relatively strongly related to high and low levels of career success, respectively (Feldman \& Ng, 2007; Seibert, 2006). Consequentially, insecurities about prestige or unemployment in the future might also be especially strong related to career success.

As a final example, the career insecurity dimensions of decreased prestige \& qualification requirements of the future employment, contractual employment conditions, and discrepancy between individual resources and work demands might explain larger portions of the variance in the outcome of job performance compared to the other dimensions. This might be because those career insecurity dimensions tap career facets closely related to the current line of work. Moreover, past research showed that a discrepancy in (individual) resources and work demands has a detrimental effect on job performance (Bakker et al., 2004; McGonagle et al., 2015). Hence, it might be that those thoughts and worries about such undesired future career aspects might also be especially strongly related to job performance.

It is beyond the scope of the paper to derive hypotheses about each and every possible contrast between all career insecurity dimensions for all outcomes. However, the examples provided here offer theoretical support for potential differences between the career insecurity dimensions when predicting an outcome. Accordingly, we formulate the following research question:

Research Question 1: What is the relative importance of the eight career insecurity dimensions for predicting the outcomes of (a) physical symptoms; (b) counterproductive work behavior; (c) workplace status; (d) career satisfaction; and (e) career turnover intentions?

\section{1 | Method}

\subsubsection{Sample and procedure (Sample \#7)}

In 2017, participants were recruited through a Swiss online-access research panel company with over 70,000 registered respondents in Switzerland ${ }^{5}$. The respondents received an incentive (i.e., four Swiss francs, approx. 4.3 U.S. dollars) for a successfully completed questionnaire (see Study 2, Part 1, Sample \#4). The participants had to be employed in at least $50 \%$ of a full-time position. Based on data quality checks (see Study 2, Part 1, Sample \#4), 3.8\% of the participants were excluded, resulting in a final sample of 1443 employees, including $50.4 \%$ women and $49.6 \%$ men. The participants were $M=38.05$ years old $(S D=9.80)$ and worked $38.45(S D=6.05)$ h per week on average within different industries and sectors (e.g., private educational system, healthcare, manufacturing industry).

\subsection{2 | Measures (Sample \#7)}

We measured multidimensional career insecurity with the $\mathrm{MU}-\mathrm{Cl}-\mathrm{S}$. All outcomes related to the frequency of physical symptoms, counterproductive work behavior, career turnover intentions, and career satisfaction were measured as in Sample \#5 (cf. Table S4 in Online Supplements). We measured workplace status using a scale developed by Djurdjevic et al. (2017). The respondents were asked to rate five items on a seven-point Likert-type scale ranging from 1 (strongly disagree) to 7 (strongly agree). A sample item is "I possess high status in my organization." Although a self-report measure, Djurdjevic et al. (2017) found significant positive correlations between self-reported and peer-reported workplace status for the same focal person. Cronbach's alphas of all applied scales are shown in Table 6. 


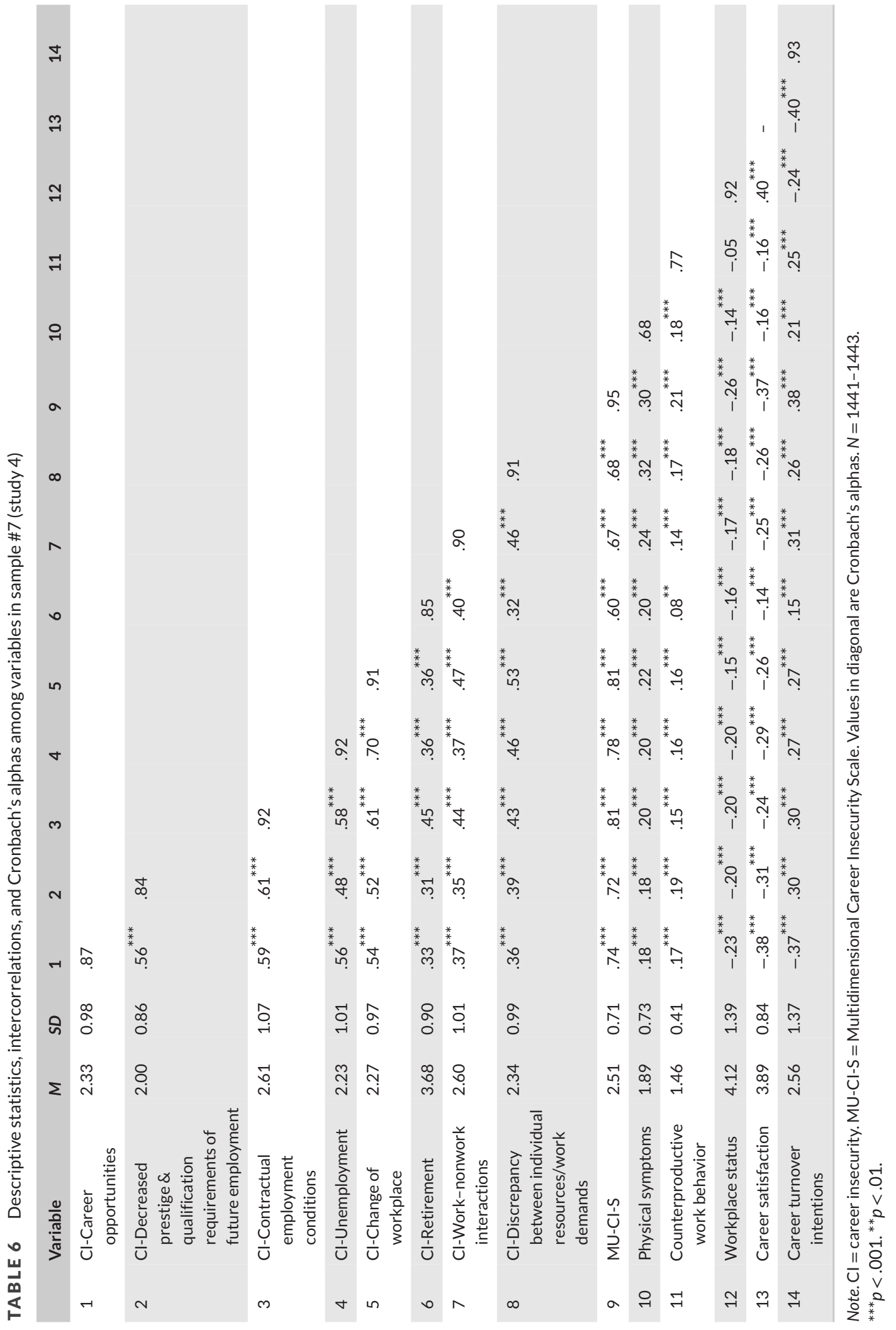




\subsection{3 | Analytical procedure}

We used RWA-Web to examine relative importance in the classic multiple regression model (Tonidandel \& LeBreton, 2015). The relative weights analysis (RWA) identifies the relative importance of each career insecurity dimension in relation to different outcomes. We estimated the statistical significance of the relative weights using a bootstrapping procedure with the RWA-Web default bootstrapping options ( $k=10,000$ replications and alpha $=.05$ ). The obtained rescaled weights provide estimates of the relative importance of the different dimensions using the metric of percentage of predicted variance attributed to each outcome variable (Tonidandel \& LeBreton, 2015).

\section{2 | Results}

\subsection{1 | Preliminary results: Correlations}

Descriptive statistics, intercorrelations, and Cronbach's alphas among variables are shown in Table 6. Overall, the size and pattern of relationships between the eight career insecurity dimensions were very similar compared to the samples used previously.

\subsection{2 | RWA results}

The detailed results highlighting the three dimensions that explain the largest portion of the variance (i.e., rescaled relative weight) for every outcome are displayed in Table 7. The results in Table 7 show that the single career insecurity dimensions explain different portions of variance in every outcome. For example, regarding workplace status, the largest portion of the explained variance was due to $\mathrm{Cl}$-Career opportunities $(23.88 \%, \mathrm{Cl} 95 \%=[0.008 ; 0.003])$, the second largest portion was due to $\mathrm{Cl}$-Decreased prestige \& qualification requirements of future employment (14.87\%, $\mathrm{Cl} 95 \%=[0.003 ; 0.023])$, and the third largest portion was due to $\mathrm{Cl}$-Unemployment $(13.81 \%, \mathrm{Cl} 95 \%=[0.003 ; 0.022])$. Across all analyses, the largest portion of explained variance was due to Cl-Discrepancy between individual resources/work demands $(44.02 \%, \mathrm{Cl} 95 \%=[0.031 ; 0.073])$ for predicting physical symptoms, and the smallest significant portion of explained variance was due to $\mathrm{Cl}$-Retirement $(1.65 \%, \mathrm{Cl} 95 \%=[0.001 ; 0.008])$ for predicting career satisfaction.

We compared whether the relative importance of each career insecurity dimension differed significantly from the other career insecurity dimensions (Tonidandel \& LeBreton, 2015). For every outcome, at least five differences between the weights of the career insecurity dimensions were significant. In sum, the descriptive results and the contrasts between the weights show that the different career insecurity dimensions explain different portions of the variance in an individual outcome.

\section{3 $\quad$ Discussion Study 4}

In Study 4, we extended the results of Study 3, shedding more light on the differential relationships of all eight career insecurity dimensions with health and well-being, job performance, career success, and career attitudes. The results showed that the career insecurity dimensions were differentially important for predicting specific outcomes. Some dimensions showed relatively stronger relationships with specific outcomes compared with other dimensions. Some dimensions showed rather small relationships compared to other dimensions but consistently explained significant portions of the variance in the majority of outcomes. Moreover, for all but one outcome (i.e., physical symptoms), seven 

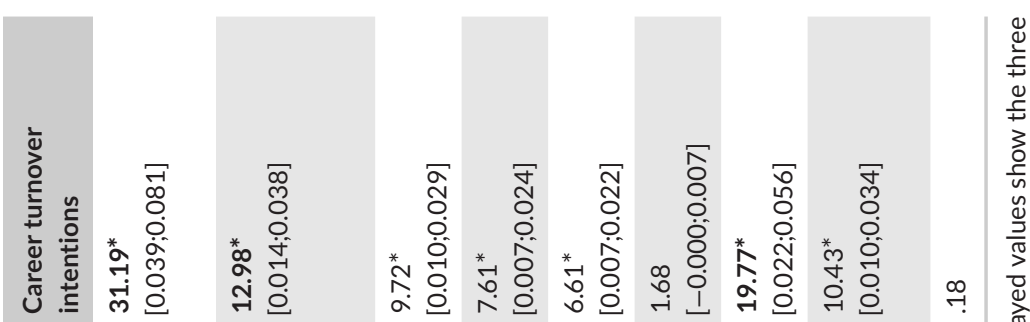

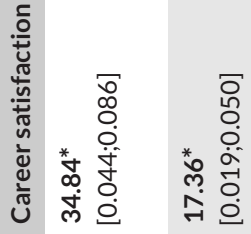

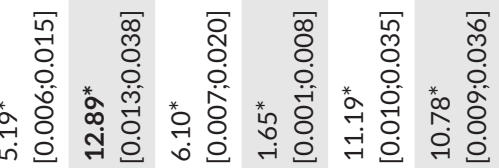

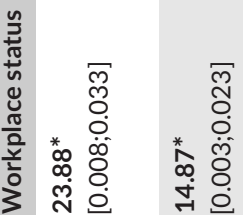

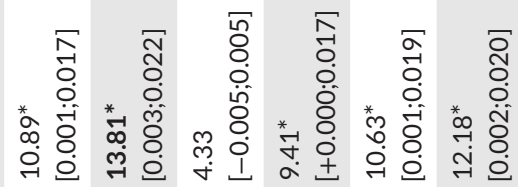

$\stackrel{\infty}{\sim}$

$\stackrel{\infty}{\rightarrow}$

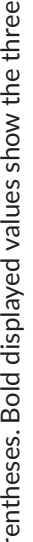

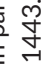

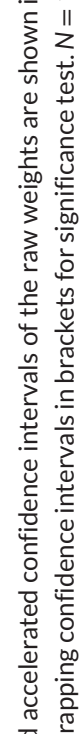

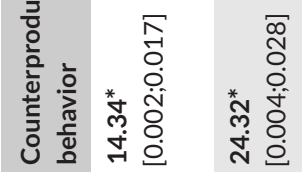

훙

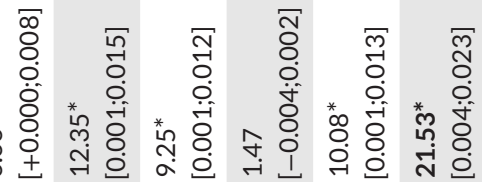

$\frac{\sqrt{n}}{\frac{n}{n}}$

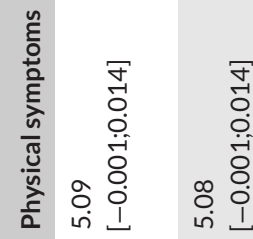

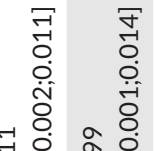

*

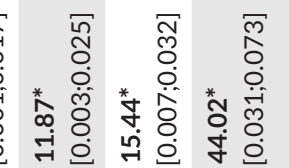

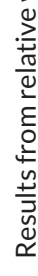

1
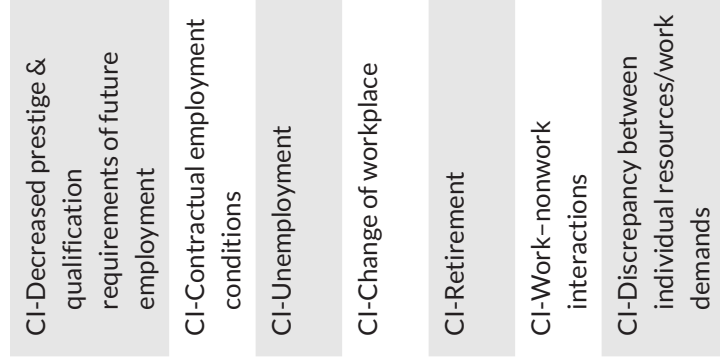
or eight career insecurity dimensions explained unique portions of variance, and every career insecurity dimension predicted significant portions of variance (with varying importance compared to the other dimensions). Therefore, we conclude that it is important to conceptualize and measure career insecurity in its entire breadth as a multidimensional construct.

\section{6 | GENERAL DISCUSSION}

This study addressed the need to explicitly consider insecurity perceptions associated with an individual's future career (C. Lee et al., 2018; Trevor-Roberts, 2006). Through four studies with seven samples using a mixed-method approach, we clarified the conceptual nature of career insecurity (Aim 1), developed and tested a new eightdimensional measure (the MU-CI-S; Aim 2), and investigated the new scale in relation to central outcomes (Aim 3). Overall, we replicated the central results associated with scale development and validation across at least two different samples. The results of the study have several implications.

\subsection{Theoretical and empirical implications for career development and insecurity research}

First, our studies provide knowledge about which thoughts and worries employees have when thinking about their future career. In doing so, we extend past one-dimensional conceptualizations of career insecurity (Colakoglu, 2011; Höge et al., 2012) to a multidimensional approach. The eight career insecurity dimensions reflect key elements in prominent career development models. $\mathrm{Cl}$-Career opportunities, $\mathrm{Cl}$-Decreased prestige \& qualification requirements of future employment, and $\mathrm{Cl}$-Contractual employment conditions are related to discrete future occupational employment situations across a person's career. These dimensions align with career models that highlight that individuals typically engage in different types of employment or jobs across their careers (Arthur et al., 1989; Schein, 1971). ClUnemployment, $\mathrm{Cl}$-Change of workplace, and $\mathrm{Cl}$-Retirement are related to different potential career transitions across a person's career. Career transitions are moves across organizational, occupational, and role boundaries, which can create both minor discontinuities and major interruptions in an individual career (Gunz et al., 2007). The dimensions align with career models that highlight lifespan approaches or role transitions over time (Hall et al., 2018; Super, 1990). Finally, $\mathrm{Cl}$-Work-nonwork interactions and Cl-Discrepancy between individual resources/work demands are related to the interaction between personal characteristics/circumstances and aspects of working life across a person's career. These dimensions align with career models that highlight the interplay between the person and contextual factors (Greenhaus \& Kossek, 2014; Gunz et al., 2011).

Second, by identifying the content of career insecurity, we extend past idiosyncratic research on college students' sources of career insecurity (Tien et al., 2005). Moreover, our conceptual approach to identifying dimensions of a construct (i.e., career insecurity) extends similar research on the dimensionality and understanding of career success. For example, some studies assumed that the subjective meaning (or understanding) of career success can best be understood in a multidimensional manner and that the underlying dimensions are best derived from subjective understandings about common content aspects of career success (Mayrhofer et al., 2016; Shockley et al., 2016). Such approaches enriched one-dimensional and narrow conceptualizations of career success. Similarly, our study conceptually enriches the field of career insecurity research.

Third, we developed and validated a psychometrically sound multidimensional scale to measure career insecurity. The results revealed that multidimensional career insecurity is related to yet distinct from a variety of other constructs: one-dimensional career insecurity, job insecurity, perceived low employability, and perceived career barriers. These results have theoretical relevance for research on insecurity in the workplace. Although existing job and one-dimensional career insecurity conceptualizations and measures are important (Colakoglu, 2011; De Witte, 
2005; Shoss, 2017), they seem to miss important aspects. Specifically, they seem to tap mostly into the unemployment dimension of career insecurity, whereas all other career insecurity dimensions (especially Cl-Retirement and $\mathrm{Cl}$-Work-nonwork interactions, see Table 3) show less empirical overlap with other insecurity measures.

On a related note, our measure of career insecurity can be used as a mean score representing the construct in its breadth or, alternatively, to probe specific dimensions. This conclusion is based on several CFA tests. On the one hand, these tests showed that career insecurity can be conceptualized and measured as a latent second-order construct. It captures employees' thoughts and worries regarding common content aspects of future career development. The tests also showed that eight correlated latent first-order factors representing the separate career insecurity dimensions fit the data equally well, hence making it possible to use distinct dimensions. Note that we assumed that career insecurity is a reflective construct; that is, perceived overall career insecurity is affecting its dimensions by triggering an insecurity-related perception process (Edwards, 2001; Fleuren et al., 2018). Therefore, we applied reflective modelling strategies (e.g., CFAs with a second-order structure).

Fourth, the relationships between career insecurity and outcomes align with hypotheses inspired by theories from stress and career management research. The results support the idea that career insecurity is a career-related stressor that exerts mainly negative effects (e.g., general: lower health and well-being; work-specific: lower job performance) due to experienced strain and a depletion of resources (Folkman et al., 1986; Hobfoll et al., 2018). In addition, career insecurity might be detrimental for career success (e.g., workplace status, career satisfaction) and individual career management (e.g., career attitudes), consistent with models on social-cognitive career management (Lent \& Brown, 2013). In sum, by integrating career insecurity in stress- and career-specific theories, the article addresses recent calls (Akkermans \& Kubasch, 2017) to bridge applied psychology and vocational behavior research, specifically occupational health and career development. Importantly, we also showed that the relationship of career insecurity to other variables cannot simply be explained as resulting from an anxious personal disposition related to negative affectivity because the relationships held after controlling for neuroticism in two samples (including one time-lagged design).

Fifth, the results of Study 4 showed that some career insecurity dimensions have a significantly stronger relationship with specific outcomes compared to other dimensions. Such differences not only highlight the usefulness of a multidimensional scale but also inform career theory. For example, Cl-Discrepancy between individual resources/work demands explains significantly more variance in physical symptoms compared to the other dimensions. This finding shows that career development and health are meaningfully related issues and calls for more interdisciplinary research between careers and occupational health psychology. Recent approaches like the sustainable career (De Vos et al., 2020; Van der Heijden et al., 2020) are already addressing such issues and might be enriched by the construct of career insecurity. As another example, $\mathrm{Cl}$-Work-nonwork interactions explain significantly more variance in career turnover intentions than $\mathrm{Cl}$-Contractual employment conditions, $\mathrm{Cl}$-Unemployment, $\mathrm{Cl}$-Change of workplace, and $\mathrm{Cl}$-Retirement. This finding indicates that work-home perspectives (Greenhaus \& Kossek, 2014) are important and that insecurities within such domains are meaningful for career attitudes and career decisions that might change the career paths of individuals.

In recent years, careers have become more insecure, and this trend will likely continue given the rise of the gig economy and digitization. Presumably, the gig economy will also affect careers and thus the career insecurity of many individuals (Spurk \& Straub, 2020). Working in the gig economy is related to more unstable employment and precariousness, which will likely increase the career insecurity dimensions of, for example, unemployment or career opportunities. In contrast, because the gig economy is also related to higher levels of autonomy and flexibility, other dimensions of career insecurity might be reduced by working in the gig economy, such as the discrepancy between individual resources/work demands or change of workplace. Another often-mentioned future trend is digitization, due to which numerous jobs or occupations might be at risk in the future (Hirschi, 2018). This might increase levels of $\mathrm{Cl}$-Change of workplace or $\mathrm{Cl}$-Prestige and the qualification requirements of future employment. 


\section{2 | Practical implications}

Regarding the applied settings, the 32 items of the MU-Cl-S represent a valid, reliable, and easy-to-understand selfassessment that can guide employees in their future career development. Such an assessment could be used within career counseling to diagnose overall career insecurity or specific insecurity profiles that allow for a customized intervention strategy. For example, diagnosing relatively high levels of $\mathrm{Cl}$-Work nonwork interactions within a counseling setting would mean that the employee and counsellor need to incorporate the employee's private life and potential close ones in the counselling process. Moreover, insecurity profiles could also be used for applied organizational settings, such as the development of career management systems or organizational retention strategies. In such a strategy, the derived career insecurity profiles could be used to develop workforce-fitted career systems or retention strategies. For example, if results show that $\mathrm{Cl}$-Retirement is a major issue compared to the other dimensions, the organization could apply intervention strategies such as (long-term) retirement planning workshops or optimizing pension plans or incentives. Such customized applications represent an economical way to reduce the most important parts of career insecurity and could thus be an interesting option from a cost/benefit standpoint.

Although such custom-fit applications are an advantage of the development of the multidimensional scale, the scale nonetheless enables the diagnosis of overall career insecurity. Regarding the results of Study 3 (criterion validity), it seems clear that both human resource management and career counselors should care about the career insecurity levels of their clients. Programs, techniques, or trainings aiming to reduce career insecurity (e.g., by developing more optimistic general attitudes or coping strategies to better deal with insecurity perceptions or implementing a more long-term and transparent intra- or extra-organizational career system) could help to increase health and well-being, job performance, career success, and career attitudes. As another possibility, programs that enhance personal and contextual resources, such as career self-management trainings (Raabe et al., 2007) or career coaching (Spurk et al., 2015), offer promise for reducing career insecurity (e.g., by increasing career optimism).

Besides applied settings, the new scale can also be useful for applied researchers. By measuring career insecurity, the scale could help inform future intervention research (e.g., career counselling effectiveness or training effectiveness), as reducing career insecurity can and should be a major aim of such career interventions. Therefore, both the overall score and all or specific single dimensions could be used as additional outcomes within evaluation studies. In addition, the new scale provides flexibility for future career insecurity research. If researchers are interested in career insecurity as a focal construct, applying the 32 items to measure all dimensions provides an attractive way to investigate career insecurity and to address dimensional research questions, for example, by deriving latent career insecurity profiles. In contrast, if specific research topics are the focus (e.g., retirement or career success), researchers might assess only the $\mathrm{Cl}$-Retirement or $\mathrm{Cl}$-Career opportunities dimensions, respectively. This would broaden the knowledge about specific insecurity content aspects.

\subsection{Limitations and future research}

The studies have some limitations that need to be addressed. First, we investigated career insecurity within a population of employed adults because they represent a large and important group within the labor market. However, our conceptualization and measurement cannot be generalized without caution to a non-working population (e.g., longterm unemployment) or to self-employed individuals or gig workers because they might, for example, interpret the items differently. In other words, not all dimensions might fit equally across different populations. Future research could focus on career insecurities of the latter groups, for example, by testing if and how the $\mathrm{MU}-\mathrm{Cl}-\mathrm{S}$ can be applied or adapted for these groups and how the levels of career insecurity differ between these groups.

Second, we derived our conceptualization and further empirical results from seven independent samples, including European and international scholar samples. As past research has shown that the meaning of career success might 
differ between Western and non-Western countries (Mayrhofer et al., 2016), the results of Studies 3 and 4 (i.e., samples from Germany and Switzerland) might therefore not be generalizable to other cultural contexts. Moreover, career systems and (tax-financed) pension coverage differ between countries, which might affect the meaning of career insecurity in this domain or its relationships with other variables. Hence, future research should investigate whether the developed scale and meaning of career insecurity remains invariant across different cultural contexts and countries.

Third, although we already included several empirical correlates and outcomes of career insecurity in Studies 2 , 3 , and 4, the nomological net of career insecurity has not been fully explored yet. Regarding outcomes of career insecurity, future research might investigate if, how, and when career insecurity leads to psychological and physical boundarylessness (Guan et al., 2019) or, in contrast, to career inaction (Verbruggen \& De Vos, 2020). Stress theories and social-cognitive career theories may provide a useful theoretical background for investigating further outcomes. Although those theories provide a solid basis for the assumed direction of relationships, career insecurity and concepts like physical symptoms, burnout, and job performance might be reciprocally related. Similar thoughts/models have occasionally been tested in job insecurity research (De Witte et al., 2016; Sverke et al., 2019). This emphasizes the need for longitudinal studies.

Related to this, although most of the empirical evidence shows that insecurity is primarily a stressor and has clear and overwhelmingly negative consequences for individuals (De Witte et al., 2016; De Witte \& Van Hootegem, in press; Sverke et al., 2019), career or work preservation behaviors might motivate individuals to exert extra effort or to show proactive behaviors to secure their careers (see Shoss, 2017 for such possibilities related to job insecurity). Career insecurity and outcomes might also show nonlinear relationships. For example, career insecurity could be negatively related with performance in the low to medium range of career insecurity, but this negative relationship might flatten out in the medium to higher range of career insecurity. Such relations have been shown within the job insecurity literature (e.g., Selenko et al., 2013) and should be tested in more detail for career insecurity ${ }^{6}$. Finally, although we controlled for potential confounding variables (e.g., neuroticism to rule out effects of anxious and fearful personal dispositions), future research could investigate more specific third variable influences on the relationships investigated here. For example, a rapid development in artificial intelligence might affect computer programmers' career insecurity and their career satisfaction and commitment simultaneously.

Fourth, we focused upon outcomes of career insecurity because we wanted to demonstrate the relevance of the construct for personal and work life as well as for career development. Future studies may also focus on predictors of career insecurity (e.g., personality, career resources like adaptability, or contextual factors like supporting networks) or develop more complex models that explain the effects on-or of-career insecurity while accounting for moderators (e.g., opportunity structures or future temporal focus as a personality trait). As another example, some of the constructs investigated here (e.g., perceived low employability and perceived career barriers) might also be seen as antecedents of career insecurity. Hence, it might be that individuals who show proactive attitudes or behaviors that enhance their employability or reduce their perceptions of barriers (Akkermans \& Kubasch, 2017) might actively regulate their career insecurity perceptions.

Finally, although we investigated different relationships of the eight career insecurity dimensions with different outcomes, future research could investigate these differences in more detail. For instance, different boundary conditions might be relevant for different career insecurity dimensions (e.g., age could be a moderator for effects of the $\mathrm{Cl}$-Retirement dimension on outcomes, such as life satisfaction or retirement planning). Moreover, as mentioned in the practical implications section, the existence of typical dimensional constellations (e.g., latent profiles) and the antecedents and outcomes of such profiles would be of specific interest for future research.

\section{7 | CONCLUSION}

Based on theoretical considerations of insecurity in work and career developmental theories, a comprehensive investigation of the construct of career insecurity was conducted. The article shows that career insecurity is an important 
construct that can be comprehensively assessed with the $\mathrm{MU}-\mathrm{Cl}-\mathrm{S}$. Career insecurity should be understood as a multidimensional construct encompassing eight specific career insecurity dimensions and showing unique relationships to different outcomes, which are highly important for employees and their future career development. $\mathrm{MU}-\mathrm{Cl}-\mathrm{S}$, the newly developed measure, provides an opportunity to overcome the limitations of past insecurity research in the workplace and highlights the need to focus more on specific short- to long-term career insecurity perceptions as an extension of insecurity research in the work and career domains.

\section{ORCID}

Annabelle Hofer (D) https://orcid.org/0000-0001-6759-1755

Andreas Hirschi (D) https://orcid.org/0000-0001-8766-3314

Nele De Cuyper (D) https://orcid.org/0000-0001-7241-9941

Hans De Witte (D) https://orcid.org/0000-0002-6691-517X

\section{ENDNOTES}

1 Past job insecurity research used the terms insecurity and uncertainty. Insecurity usually refers to undesired aspects of the job that might occur or not occur, while uncertainty involves not knowing something for sure (without having worries) or (in)stability. Moreover, uncertainty is usually operationalized in the response format of the scale (e.g.; $1=$ not sure at all, $5=$ totally sure), whereas insecurity is addressed in the item formulation per se. We refer to insecurity and therefore use this term to avoid confusion with past insecurity research.

2 We searched the available time span and used the following search terms within the field (a) title and (b) title, abstract, keywords: "career insecurity"; "career uncertainty"; "career instability"; "career precariousness"; "work insecurity"; "work uncertainty"; "work instability"; "precariousness"; "occupational insecurity"; "occupational uncertainty"; "occupational instability"; and "occupational precariousness." We used this broad search strategy because we already knew that research on career-related insecurities is scarce, and we did not want to miss a potentially relevant article. Moreover, we know from past research that the terms "insecurity," "uncertainty," and "instability" are used interchangeably despite their conceptual differences. Finally, we did not search for "job insecurity" because we believe this construct is meaningfully different from career insecurity.

${ }^{3}$ As an important note regarding our procedure, Samples \#4 to \#7 from the different online surveys 3 to 6 , respectively (see Online Supplements Tables S1 and S2), were used for different purposes. We were careful to avoid any data overlap (e.g., exploratory and confirmatory data analyses were conducted in fully independent samples). However, to conduct insightful replications across samples, we will report some analyses across several samples. For example, the CFA factor structure is tested in every available sample. However, due to space limitations, we will not report all of the results within the main document; instead, we will report some results in the Online Supplements (e.g., the factor loadings of the CFAs from the Samples \#5 to \#7, cf. Table S3). To save space, we will describe each sample and the related measures only when the sample is mentioned the first time in the manuscript. Table $\mathrm{S} 4$ in the Online Supplements provides an overview of the measured variables from Samples \#4 to \#7 and lists the parts of the manuscript in which the samples have been used. Table $\mathrm{S} 5$ gives an overview of all Cronbach's alphas of all measures across these samples.

${ }^{4}$ All data collections were based on the German language version of the scale. For this paper, the scale items were systematically translated from German into English in collaboration with native English speakers who were also fluent in German. During the translation process, we took care that all relevant career insecurity characteristics (e.g., unsureness and undesirability) were kept in the English translation of the scale presented in Table 2.

${ }^{5}$ A partial dataset $(N=728)$ was used in Hofer et al. (2021). There is no overlap in the used constructs.

${ }^{6}$ We tested curvilinear effects by adding a quadratic career insecurity term to all incremental validity analyses presented in this paper. The results showed two significant curvilinear relationships within 16 analyses. We found an effect of quadratic $\mathrm{MU}-\mathrm{Cl}-\mathrm{S}$ on in-role behavior within sample \#5. The negative correlation slows down with increasing MU-Cl-S, which can be seen as a stabilization of performance with increasingly rising MU-CI-S. Moreover, we found an effect of quadratic MU-CI-S at T1 on physical symptoms at T2. Particularly in the case of high expressions of MU-Cl-S, the physical symptoms increased further.

\section{ACKNOWLEDGMENT}

This research was supported by a grant from the Swiss National Science Foundation (SNSF, project number: 100019_162680). 


\section{DATA AVAILABILITY STATEMENT}

The data that support the findings of this study are available from the corresponding author upon reasonable request.

\section{REFERENCES}

Abele, A. E., \& Spurk, D. (2009). The longitudinal impact of self-efficacy and career goals on objective and subjective career success. Journal of Vocational Behavior, 74(1), 53-62. https://doi.org/10.1016/j.jvb.2008.10.005

Adams, G. A., King, L. A., \& King, D. W. (1996). Relationships of job and family involvement, family social support, and workfamily conflict with job and life satisfaction. Journal of Applied Psychology, 81(4), 411-420. https://doi.org/10.1037/00219010.81.4.411

Akkermans, J., \& Kubasch, S. (2017). \#Trending topics in careers: A review and future research agenda. Career Development International, 22(6), 586-627. https://doi.org/10.1108/CDI-08-2017-0143

Anderson, J. C., \& Gerbing, D. W. (1991). Predicting the performance of measures in a confirmatory factor analysis with a pretest assessment of their substantive validities. Journal of Applied Psychology, 76(5), 732-740. https://doi.org/10.1037/ 0021-9010.76.5.732

Arthur, M. B., Hall, D. T., \& Lawrence, B. S. (1989). Handbook of career theory. Cambridge University Press. https://doi.org/10. 1017/CBO9780511625459

Aydogdu, S., \& Asikgil, B. (2011). An empirical study of the relationship among job satisfaction, organizational commitment and turnover intention. International Review of Management and Marketing, 1(3), 43-53. https://dergipark.org.tr/en/pub/irmm/ issue/32068/354976?publisher=http-www-cag-edu-tr-ilhan-ozturk

Bakker, A. B., Demerouti, E., \& Verbeke, W. (2004). Using the job demands-resources model to predict burnout and performance. Human Resource Management, 43(1), 83-104. https://doi.org/10.1002/hrm.20004

Bambacas, M., \& Kulik, C. T. (2013). Job embeddedness in China: How HR practices impact turnover intentions. The International Journal of Human Resource Management, 24(10), 1933-1952. https://doi.org/10.1080/09585192.2012.725074

Bandura, A. (1986). Social foundations of thought and action: A social cognitive theory. Prentice Hall.

Barthauer, L., Kaucher, P., Spurk, D., \& Kauffeld, S. (2020). Burnout and career (un) sustainability: Looking into the Blackbox of burnout triggered career turnover intentions. Journal of Vocational Behavior, 117, Article 103334. https://doi.org/10.1016/ j.jvb.2019.103334

Brady, D. L., Brown, D. J., \& Liang, L. H. (2017). Moving beyond assumptions of deviance: The reconceptualization and measurement of workplace gossip. Journal of Applied Psychology, 102(1), 1-25. https://doi.org/10.1037/apl0000164

Braun, V., \& Clarke, V. (2006). Using thematic analysis in psychology. Qualitative Research in Psychology, 3(2), 77-101. https: //doi.org/10.1191/1478088706qp063oa

Byrne, B. M. (2005). Factor analytic models: Viewing the structure of an assessment instrument from three perspectives. Journal of Personality Assessment, 85(1), 17-32. https://doi.org/10.1207/s15327752jpa8501_02

Chen, G., Gully, S. M., \& Eden, D. (2001). Validation of a new general self-efficacy scale. Organizational Research Methods, 4(1), 62-83. https://doi.org/10.1177/109442810141004

Cheng, G. H. L., \& Chan, D. K. S. (2008). Who suffers more from job insecurity? A meta-analytic review. Applied Psychology, 57(2), 272-303. https://doi.org/10.1111/j.1464-0597.2007.00312.x

Cheung, G. W., \& Rensvold, R. B. (2002). Evaluating goodness-of-fit indexes for testing measurement invariance. Structural Equation Modeling, 9(2), 233-255. https://doi.org/10.1207/S15328007SEM0902_5

Colakoglu, S. N. (2011). The impact of career boundarylessness on subjective career success: The role of career competencies, career autonomy, and career insecurity. Journal of Vocational Behavior, 79(1), 47-59. https://doi.org/10.1016/j.jvb.2010.09. 011

Colwell, S. R. (2016). The composite reliability calculator. Technical Report. https://doi.org/10.13140/RG.2.1.4298.088.

Creswell, J. W. (2009). Research design. Qualitative, quantitative and mixed methods approaches (3 ed.). Sage Publications.

De Cuyper, N., Mäkikangas, A., Kinnunen, U., Mauno, S., \& Witte, H. D. (2012). Cross-lagged associations between perceived external employability, job insecurity, and exhaustion: Testing gain and loss spirals according to the conservation of resources theory. Journal of Organizational Behavior, 33(6), 770-788. https://doi.org/10.1002/job.1800

De Cuyper, N., Mauno, S., Kinnunen, U., \& Mäkikangas, A. (2011). The role of job resources in the relation between perceived employability and turnover intention: A prospective two-sample study. Journal of Vocational Behavior, 78(2), 253263. https://doi.org/10.1016/j.jvb.2010.09.008

De Vos, A., Van der Heijden, B. I., \& Akkermans, J. (2020). Sustainable careers: Towards a conceptual model. Journal of Vocational Behavior, 117, Article 103196. https://doi.org/10.1016/j.jvb.2018.06.011

De Witte, H. (2000). Arbeidsethos en jobonzekerheid: meting en gevolgen voor welzijn, tevredenheid en inzet op het werk [Work ethic and job insecurity: Assessment and consequences for well-being, satisfaction and performance at work]. In (R. Bouwen, K. De Witte, H. De Witte, \& T. Taillieu Eds.), Van groep naar gemeenschap [From group to community]. Garant. Liber Amicorum Prof. Dr. Leo Lagrou. 
De Witte, H. (2005). Job insecurity: Review of the international literature on definitions, prevalence, antecedents and consequences. SA Journal of Industrial Psychology, 31(4), 1-6. https://doi.org/10.4102/sajip.v31i4.200

De Witte, H., Pienaar, J., \& De Cuyper, N. (2016). Review of 30 years of longitudinal studies on the association between job insecurity and health and well-being: Is there causal evidence? Australian Psychologist, 51(1), 18-31. https://doi.org/10.1111/ap. 12176

De Witte, H., \& Van Hootegem, A. (in press). Job insecurity: Challenge or hindrance stressor? Review of the evidence and empirical test on entrepreneurs. In (C. Korunka Ed.), Flexible working practices and approaches: Psychological and social implications of a multifaceted phenomenon. Springer.

Demerouti, E., Bakker, A. B., Vardakou, I., \& Kantas, A. (2003). The convergent validity of two burnout instruments: A multitraitmultimethod analysis. European Journal of Psychological Assessment, 19(1), 12-23. https://doi.org/10.1027//1015-5759.19. 1.12

DeSimone, J. A., Harms, P. D., \& DeSimone, A. J. (2015). Best practice recommendations for data screening. Journal of Organizational Behavior, 36(2), 171-181. https://doi.org/10.1002/job.1962

Djurdjevic, E., Stoverink, A. C., Klotz, A. C., Koopman, J., da Motta Veiga, S. P., Yam, K. C., \& Chiang, J. T.-J. (2017). Workplace status: The development and validation of a scale. Journal of Applied Psychology, 102(7), 1124-1147. https://doi.org/10. 1037/apl0000202

Edwards, J. R. (2001). Multidimensional constructs in organizational behavior research: An integrative analytical framework. Organizational Research Methods, 4(2), 144-192. https://doi.org/10.1177/109442810142004

Ellonen, N., \& Nätti, J. (2015). Job insecurity and the unemployment rate: Micro-and macro-level predictors of perceived job insecurity among Finnish employees 1984-2008. Economic and Industrial Democracy, 36(1), 51-71. https://doi.org/10. $1177 / 0143831 \times 13495720$

Feldman, D. C., \& Ng, T. W. H. (2007). Careers: Mobility, embeddedness, and success. Journal of Management, 33(3), 350-377. https://doi.org/10.1177/0149206307300815

Felfe, J., Schmook, R., \& Six, B. (2006). Die Bedeutung kultureller Wertorientierungen für das Commitment gegenüber der Organisation, dem Vorgesetzten, der Arbeitsgruppe und der eigenen Karriere. Zeitschrift für Personalpsychologie, 5(3), 94107. https://doi.org/10.1026/1617-6391.5.3.94

Fleuren, B. P., van Amelsvoort, L. G., Zijlstra, F. R., de Grip, A., \& Kant, I. (2018). Handling the reflective-formative measurement conundrum: A practical illustration based on sustainable employability. Journal of Clinical Epidemiology, 103, 71-81. https: //doi.org/10.1016/j.jclinepi.2018.07.007

Folkman, S., Lazarus, R. S., Gruen, R. J., \& DeLongis, A. (1986). Appraisal, coping, health status, and psychological symptoms. Journal of Personality and Social Psychology, 50(3), 571-579. https://doi.org/10.1037/0022-3514.50.3.571

Ford, J. K., MacCallum, R. C., \& Tait, M. (1986). The application of exploratory factor analysis in applied psychology: A critical review and analysis. Personnel Psychology, 39(2), 291-314. https://doi.org/10.1111/j.1744-6570.1986.tb00583.x

Fornell, C., \& Larcker, D. F. (1981). Evaluating structural equation models with unobservable variables and measurement error. Journal of Marketing Research, 18(1), 39-50. https://doi.org/10.1177/002224378101800104

Gesthuizen, M., \& Wolbers, M. H. (2011). Late career instability and the transition into retirement of older workers in the Netherlands. In (H.-P. Blossfeld, S. Buchholz, \& K. Kurz Eds.), Aging populations, globalization and the labor market: Comparing late working life and retirement in modern societies (pp. 65-90). Edward Elgar. https://doi.org/10.4337/9781849805858

Gould, S. (1979). Characteristics of career planners in upwardly mobile occupations. Academy of Management Journal, 22(3), 539-550. https://doi.org/10.2307/255743

Graham, J. W., \& Coffman, D. L. (2012). Structural equation modeling with missing data. In (R. H. Hoyle Ed.), Handbook of structural equation modeling (pp. 277-295). The Guilford Press.

Greenhalgh, L., \& Rosenblatt, Z. (1984). Job insecurity: Toward conceptual clarity. Academy of Management Review, 9(3), 438448. https://doi.org/10.5465/amr.1984.4279673

Greenhaus, J. H., \& Kossek, E. E. (2014). The contemporary career: A work-home perspective. Annual Review of Organizational Psychology and Organizational Behavior, 1(1), 361-388. https://doi.org/10.1146/annurev-orgpsych-031413-091324

Greenhaus, J. H., Parasuraman, S., \& Wormley, W. M. (1990). Effects of race on orgnizational experiences, job performance evaluations, and career outcomes. Academy of Management Journal, 33(1), 64-86. https://doi.org/10.2307/256352

Guan, Y., Arthur, M. B., Khapova, S. N., Hall, R. J., \& Lord, R. G. (2019). Career boundarylessness and career success: A review, integration and guide to future research. Journal of Vocational Behavior, 110 (Part B), 390-402. https://doi.org/10.1016/j. jvb.2018.05.013

Gunz, H., Mayrhofer, W., \& Tolbert, P. (2011). Career as a social and political phenomenon in the globalized economy. Organization Studies, 32(12), 1613-1620. https://doi.org/10.1177/0170840611421239

Gunz, H., Peiperl, M., \& Tzabbar, D. (2007). Boundaries in the study of career. In (H. P. Gunz \& M. A. Peiperl Eds.), Handbook of career studies (pp. 471-494). Sage. https://doi.org/10.4135/9781412976107.n24 
Hall, D. T., Yip, J., \& Doiron, K. (2018). Protean careers at work: Self-direction and values orientation in psychological success. Annual Review of Organizational Psychology and Organizational Behavior, 5(1), 129-156. https://doi.org/10.1146/annurevorgpsych-032117-104631

Hellgren, J., Sverke, M., \& Isaksson, K. (1999). A two-dimensional approach to job insecurity: Consequences for employee attitudes and well-being. European Journal of Work and Organizational Psychology, 8(2), 179-195. https://doi.org/10.1080/ 135943299398311

Heslin, P. A. (2003). Self- and other-referent criteria of success. Journal of Career Assessment, 11(3), 262-286. https://doi.org/ 10.1177/1069072703254500

Hinkin, T. R. (1995). A review of scale development practices in the study of organizations. Journal of Management, 21(5), 967988. https://doi.org/10.1177/014920639502100509

Hinkin, T. R. (1998). A brief tutorial on the development of measures for use in survey questionnaires. Organizational Research Methods, 1(1), 104-121. https://doi.org/10.1177/109442819800100106

Hirschi, A. (2018). The fourth industrial revolution: Issues and implications for career research and practice. The Career Development Quarterly, 66(3), 192-204. https://doi.org/10.1002/cdq.12142

Hirschi, A., \& Freund, P. A. (2014). Career engagement: Investigating intraindividual predictors of weekly fluctuations in proactive career behaviors. The Career Development Quarterly, 62(1), 5-20. https://doi.org/10.1002/j.2161-0045.2014.00066.x

Hirschi, A., Nagy, N., Baumeler, F., Johnston, C. S., \& Spurk, D. (2018). Assessing key predictors of career success: Development and validation of the career resources questionnaire. Journal of Career Assessment, 26(2), 338-358. https://doi.org/10.1177/ 1069072717695584

Hobfoll, S. E., Halbesleben, J., Neveu, J.-P., \& Westman, M. (2018). Conservation of resources in the organizational context: The reality of resources and their consequences. Annual Review of Organizational Psychology and Organizational Behavior, 5 , 103-128. https://doi.org/10.1146/annurev-orgpsych-032117-104640

Hofer, A., Spurk, D., \& Hirschi, A. (2021). When and why do negative organization-related career shocks impair career optimism? A conditional indirect effect model. Career Development International, 26(4), 467-494. https://doi.org/10.1108/CDI12-2018-0299

Höge, T., Brucculeri, A., \& Iwanowa, A. N. (2012). Karriereunsicherheit, Zielkonflikte und Wohlbefinden bei Nachwuchswissenschaftlerinnen und -wissenschaftlern [career insecurity, conflict of aims and well-being in junior scientists]. Zeitschrift für Arbeits- und Organisationspsychologie A\&O, 56(4), 159-172. https://doi.org/10.1026/0932-4089/a000088

Holland, J. L., Daiger, D. C., \& Power, P. G. (1980). My vocational situation. Consulting Psychologists Press.

Hu, L.-T., \& Bentler, P. M. (1998). Fit indices in covariance structure modeling: Sensitivity to underparameterized model misspecification. Psychological Methods, 3(4), 424-453. https://doi.org/10.1037/1082-989X.3.4.424

Jiang, L., \& Lavaysse, L. M. (2018). Cognitive and affective job insecurity: A meta-analysis and a primary study. Journal of Management, 44(6), 2307-2342. https://doi.org/10.1177/0149206318773853

Kinnunen, U., Geurts, S., \& Mauno, S. (2004). Work-to-family conflict and its relationship with satisfaction and wellbeing: a one-year longitudinal study on gender differences. Work \& Stress, 18(1), 1-22. https://doi.org/10.1080/ 02678370410001682005

Kline, R. B. (2011). Principles and practice of structural equation modeling (3rd ed.). Guilford Press.

Körner, A., Lechner, C. M., Pavlova, M. K., \& Silbereisen, R. K. (2015). Goal engagement in coping with occupational uncertainty predicts favorable career-related outcomes. Journal of Vocational Behavior, 88, 174-184. https://doi.org/10.1016/j. jvb.2015.03.001

Kraimer, M. L., Seibert, S. E., Wayne, S. J., Liden, R. C., \& Bravo, J. (2011). Antecedents and outcomes of organizational support for development: The critical role of career opportunities. Journal of Applied Psychology, 96(3), 485-500. https://doi.org/10. 1037/a0021452

Kukla, M., Salyers, M. P., Strasburger, A. M., Johnson-Kwochka, A., Amador, E., \& Lysaker, P. H. (2019). Work-focused cognitive behavioral therapy to complement vocational services for people with mental illness: Pilot study outcomes across a 6-month posttreatment follow-up. Psychiatric Rehabilitation Journal, 42(2), 366-371. https://doi.org/10.1037/prj0000365

Lee, C., Huang, G.-H., \& Ashford, S. J. (2018). Job insecurity and the changing workplace: recent developments and the future trends in job insecurity research. Annual Review of Organizational Psychology and Organizational Behavior, 5, 335-359. https: //doi.org/10.1146/annurev-orgpsych-032117-104651

Lee, C. I. S. G., Felps, W., \& Baruch, Y. (2014). Toward a taxonomy of career studies through bibliometric visualization. Journal of Vocational Behavior, 85(3), 339-351. https://doi.org/10.1016/j.jvb.2014.08.008

Lent, R. W., \& Brown, S. D. (2013). Social cognitive model of career self-management: Toward a unifying view of adaptive career behavior across the life span. Journal of Counseling Psychology, 60(4), 557-568. https://doi.org/10.1037/a0033446

Luzzo, D. A. (1993). Value of career-decision-making self-efficacy in predicting career-decision-making attitudes and skills. Journal of Counseling Psychology, 40(2), 194-199. https://doi.org/10.1037/0022-0167.40.2.194

Mak, A. S., \& Mueller, J. (2000). Job insecurity, coping resources and personality dispositions in occupational strain. Work \& Stress, 14(4), 312-328. https://doi.org/10.1080/02678370010022462 
Mayrhofer, W., Briscoe, J. p., Hall, D. T., Dickmann, M., Dries, N., Dysvik, A., Kaše, R., Parry, E., \& Unite, J. (2016). Career success across the globe: Insights from the 5C Project. Organizational Dynamics, 45, 197-205. https://doi.org/10.1016/j.orgdyn. 2016.07.005

McGonagle, A. K., Fisher, G. G., Barnes-Farrell, J. L., \& Grosch, J. W. (2015). Individual and work factors related to perceived work ability and labor force outcomes. Journal of Applied Psychology, 100(2), 376-398. https://doi.org/10.1037/a0037974

Meyer, J. P., Allen, N. J., \& Smith, C. A. (1993). Commitment to organizations and occupations: Extension and test of a threecomponent conceptualization. Journal of Applied Psychology, 78(4), 538-551. https://doi.org/10.1037/0021-9010.78.4.538

Muthén, L. K., \& Muthén, B. O. (1998-2015). Mplus user's guide (7th ed.). Muthén \& Muthén.

Ng, T. W. H., Eby, L. T., Sorensen, K. L., \& Feldman, D. C. (2005). Predictors of objective and subjective career success: A metaanalysis. Personnel Psychology, 58(2), 367-408. https://doi.org/10.1111/j.1744-6570.2005.00515.x

Ng, T. W. H., \& Feldman, D. C. (2014a). A conservation of resources perspective on career hurdles and salary attainment. Journal of Vocational Behavior, 85(1), 156-168. https://doi.org/10.1016/j.jvb.2014.05.008

Ng, T. W. H., \& Feldman, D. C. (2014b). Subjective career success: A meta-analytic review. Journal of Vocational Behavior, 85(2), 169-179. https://doi.org/10.1016/j.jvb.2014.06.001

Ortlieb, R., \& Weiss, S. (2018). What makes academic careers less insecure? The role of individual-level antecedents. Higher Education, 76(4), 571-587. https://doi.org/10.1007/s10734-017-0226-x

Pavlova, M. K., \& Silbereisen, R. K. (2014). Coping with occupational uncertainty and formal volunteering across the life span. Journal of Vocational Behavior, 85(1), 93-105. https://doi.org/10.1016/j.jvb.2014.05.005

Pennebaker, J. W. (1982). The psychology of physical symptoms. Springer. https://doi.org/10.1007/978-1-4613-8196-9

Peterson, R. A. (2000). A meta-analysis of variance accounted for and factor loadings in exploratory factor analysis. Marketing Letters, 11(3), 261-275. https://doi.org/10.1023/A:1008191211004

Pienaar, J., De Witte, H., Hellgren, J., \& Sverke, M. (2013). The cognitive/affective distinction of job insecurity: Validation and differential relations. Southern African Business Review, 17(2), 1-22. https://www.ajol.info/index.php/sabr/article/view/ 110912

Raabe, B., Frese, M., \& Beehr, T. A. (2007). Action regulation theory and career self-management. Journal of Vocational Behavior, 70(2), 297-311. https://doi.org/10.1016/j.jvb.2006.10.005

Rammstedt, B., \& John, O. P. (2005). Kurzversion des big five inventory (BFI-K). Diagnostica, 51(4), 195-206. https://doi.org/ 10.1026/0012-1924.51.4.195

Raykov, T. (1997). Estimation of composite reliability for congeneric measures. Applied Psychological Measurement, 21(2), 173184. https://doi.org/10.1177/01466216970212006

Rothwell, A., \& Arnold, J. (2007). Self-perceived employability: Development and validation of a scale. Personnel Review, 36(1), 23-41. https://doi.org/10.1108/00483480710716704

Sandelowski, M. (1995). Sample size in qualitative research. Research in Nursing \& Health, 18(2), 179-183. https://doi.org/10. 1002/nur.4770180211

Saumure, K., \& Given, L. M. (2008). Data saturation. In (L. M. Given Ed.), The SAGE encyclopedia of qualitative research methods (Vol., 1, pp. 195-196). Sage Publications.

Schein, E. H. (1971). The individual, the organization, and the career: A conceptual scheme. The Journal of Applied Behavioral Science, 7(4), 401-426. https://doi.org/10.1177/002188637100700401

Schmitt, C. (2012). Labour market integration, occupational uncertainties, and fertility choices in Germany and the UK. Demographic Research, 26, 253-292, Article 12. https://doi.org/10.4054/DemRes.2012.26.12

Scott-Marshall, H. (2010). The social patterning of work-related insecurity and its health consequences. Social Indicators Research, 96(2), 313-337. https://doi.org/10.1007/s11205-009-9480-3

Seibert, S. E. (2006). Career success. In (J. H. Greenhaus \& G. A. Callanan Eds.), Encyclopedia of career development. Sage Publications.

Selenko, E., Mäkikangas, A., Mauno, S., \& Kinnunen, U. (2013). How does job insecurity relate to self-reported job performance? Analysing curvilinear associations in a longitudinal sample. Journal of Occupational and Organizational Psychology, 86(4), 522-542. https://doi.org/10.1111/joop.12020

Shockley, K. M., Ureksoy, H., Rodopman, O. B., Poteat, L. F., \& Dullaghan, T. R. (2016). Development of a new scale to measure subjective career success: A mixed-methods study. Journal of Organizational Behavior, 37(1), 128-153. https://doi.org/10. 1002/job.2046

Shoss, M. K. (2017). Job insecurity: An integrative review and agenda for future research. Journal of Management, 43(6), 19111939. https://doi.org/10.1177/0149206317691574

Spector, P. E., Bauer, J. A., \& Fox, S. (2010). Measurement artifacts in the assessment of counterproductive work behavior and organizational citizenship behavior: Do we know what we think we know? Journal of Applied Psychology, 95(4), 781-790. https://doi.org/10.1037/a0019477 
Spurk, D., Abele, A. E., \& Volmer, J. (2011). The career satisfaction scale: Longitudinal measurement invariance and latent growth analysis. Journal of Occupational and Organizational Psychology, 84(2), 315-326. https://doi.org/10.1111/j.20448325.2011.02028.x

Spurk, D., Hofer, A., Burmeister, A., Muehlhausen, J., \& Volmer, J. (2019). Occupational commitment from a life span perspective: An integrative review and a research outlook. Career Development International, 24(3), 190-221. https://doi.org/10. 1108/CDI-07-2018-0184

Spurk, D., Kauffeld, S., Barthauer, L., \& Heinemann, N. S. R. (2015). Fostering networking behavior, career planning and optimism, and subjective career success: An intervention study. Journal of Vocational Behavior, 87, 134-144. https://doi.org/10. 1016/j.jvb.2014.12.007

Spurk, D., Kauffeld, S., Meinecke, A. L., \& Ebner, K. (2016). Why do adaptable people feel less insecure? Indirect effects of career adaptability on job and career insecurity via two types of perceived marketability. Journal of Career Assessment, 24(2), 289306. https://doi.org/10.1177/1069072715580415

Spurk, D., \& Straub, C. (2020). Flexible employment relationships and careers in times of the COVID-19 pandemic. Journal of Vocational Behavior, 119, Article 103435. https://doi.org/10.1016/j.jvb.2020.103435

Sullivan, S. E., \& Baruch, Y. (2009). Advances in career theory and research: A critical review and agenda for future exploration. Journal of Management, 35(6), 1542-1571. https://doi.org/10.1177/0149206309350082

Super, D. E. (1953). A theory of vocational development. American Psychologist, 8(5), 185-190. https://doi.org/10.1037/ h0056046

Super, D. E. (1990). A life-span, life-space approach to career development. In (D. Brown \& L. Brooks Eds.), Career choice and development: Applying contemporary theories to practice (2nd ed.). (pp. 197-261). Jossey-Bass. http://search.epnet.com/login. aspx?direct=true\&db=psyh\&an=1990-97532-007

Sverke, M., Hellgren, J., \& Näswall, K. (2002). No security: A meta-analysis and review of job insecurity and its consequences. Journal of Occupational Health Psychology, 7(3), 242-264. https://doi.org/10.1037//1076-8998.7.3.242

Sverke, M., Låstad, L., Hellgren, J., Richter, A., \& Näswall, K. (2019). A meta-analysis of job insecurity and employee performance: Testing temporal aspects, rating source, welfare regime, and union density as moderators. International Journal of Environmental Research and Public Health, 16(14), Article 2536. https://doi.org/10.3390/ijerph16142536

Tien, H.-L. S., Lin, C.-H., \& Chen, S.-C. (2005). A grounded analysis of career uncertainty perceived by college students in taiwan. The Career Development Quarterly, 54(2), 162-174. https://doi.org/10.1002/j.2161-0045.2005.tb00148.x

Tonidandel, S., \& LeBreton, J. M. (2015). RWA web: A free, comprehensive, web-based, and user-friendly tool for relative weight analyses. Journal of Business and Psychology, 30(2), 207-216. https://doi.org/10.1007/s10869-014-9351-z

Trevor-Roberts, E. (2006). Are you sure? the role of uncertainty in career. Journal of Employment Counseling, 43(3), 98-116. https://doi.org/10.1002/j.2161-1920.2006.tb00010.x

Van der Heijden, B., De Vos, A., Akkermans, J., Spurk, D., Semeijn, J., Van der Veldek, M., \& Fugate, M. (2020). Sustainable careers across the lifespan: Moving the field forward. Journal of Vocational Behavior, 117, 1-9, Article 103344. https://doi.org/10. 1016/j.jvb.2019.103344

Van Eetveldt, M. W., Van de Ven, N., Van den Tooren, M., \& Versteeg, R. C. (2013). The importance of career insecurity for turnover intentions in the Dutch military. Military Psychology, 25(5), 489-501. https://doi.org/10.1037/mil0000016

Vander Elst, T., De Cuyper, N., Baillien, E., Niesen, W., \& De Witte, H. (2016). Perceived control and psychological contract breach as explanations of the relationships between job insecurity, job strain and coping reactions: Towards a theoretical integration. Stress and Health, 32(2), 100-116. https://doi.org/10.1002/smi.2584

Vander Elst, T., De Witte, H., \& De Cuyper, N. (2014). The Job Insecurity Scale: A psychometric evaluation across five European countries. European Journal of Work and Organizational Psychology, 23(3), 364-380. https://doi.org/10.1080/1359432X. 2012.745989

Verbruggen, M., \& De Vos, A. (2020). When people don't realize their career desires: Toward a theory of career inaction. Academy of Management Review, 45(2), 376-394. https://doi.org/10.5465/amr.2017.0196

Wang, M., \& Wanberg, C. R. (2017). 100 years of applied psychology research on individual careers: From career management to retirement. Journal of Applied Psychology, 102(3), 546-563. https://doi.org/10.1037/apl0000143

Wanous, J. P., Reichers, A. E., \& Hudy, M. J. (1997). Overall job satisfaction: How good are single-item measures? Journal of Applied Psychology, 82(2), 247-252. https://doi.org/10.1037/0021-9010.82.2.247

Warren, C. (2001). Qualitative interviewing. In (J. F. Gubrium \& J. A. Holstein Eds.), Handbook of interview research (pp. 83-103). SAGE Publications, Inc. https://doi.org/10.4135/9781412973588

Williams, L. J., \& Anderson, S. E. (1991). Job satisfaction and organizational commitment as predictors of organizational citizenship and in-role behaviors. Journal of Management, 17(3), 601-617. https://doi.org/10.1177/014920639101700305

Wright, T. A., Quick, J. C., Hannah, S. T., \& Blake Hargrove, M. (2017). Best practice recommendations for scale construction in organizational research: The development and initial validation of the Character Strength Inventory (CSI). Journal of Organizational Behavior, 38(5), 615-628. https://doi.org/10.1002/job.2180 
Zhu, D., Kim, P. B., Milne, S., \& Park, I.-J. (2020). A meta-analysis of the antecedents of career commitment. Journal of Career Assessment, 29(3), 502-524. https://doi.org/10.1177/1069072720956983

\section{SUPPORTING INFORMATION}

Additional supporting information may be found in the online version of the article at the publisher's website.

How to cite this article: Spurk, D., Hofer, A., Hirschi, A., De Cuyper, N., \& De Witte, H. (2022). Conceptualizing career insecurity: Toward a better understanding and measurement of a multidimensional construct.

Personnel Psychology, 1-42. Advance online publication. https://doi.org/10.1111/peps.12493 